\title{
Calling for Change? Innovation, diffusion, and the energy impacts of global mobile telephony
}

\author{
Nuno Bento \\ Instituto Universitário de Lisboa (ISCTE-IUL), DINÂMIA'CET, Av. das Forças Armadas, Edifício ISCTE, Sala 2N19, 1649- \\ 026 Lisboa, Portugal, Tel.: (+351) 916416087 | Fax: (+351) 2179400 42. Nuno.Bento@iscte.pt \\ Sustainability Science Program, Kennedy School of Government, Harvard University, Mailbox 117, 79 JFK street, \\ Cambridge, MA 02138 United States \\ Transitions to New Technologies Program, International Institute for Applied Systems Analysis (IIASA), \\ Schlossplatz 1, A-2361 Laxenburg, Austria
}

June 2016

\begin{abstract}
Few technologies in history diffused as intensively and fast as mobile phones, to the point where they have become the most democratic technology. The article analyzes historical patterns of mobile phone growth and their effects in energy needs. Through an empirical analysis employing diffusion models on data for 227 countries between 1980 and 2010, it is concluded that global demand may saturate at around one subscription per person and the diffusion of mobile-broadband connection has contributed to sustain growth. Demand has already showed signs of saturation in developed countries, while there is still potential for growth in developing countries. Impacts on energy consumption are assessed with the help of a field trial. Even though the energy consumed in phone charging was not very significant (6$8 \mathrm{TWh}$ ) in 2010, it becomes substantially higher when infrastructural needs are included (93TWh). The actual trends suggest that mobile communication might have a sizeable direct effect on energy consumption-although the net impact on energy demand is more difficult to estimate. This can become an issue in developing countries, where the adoption of mobile phones is catching-up rapidly with the world average, in a context of generalized increasing electricity demand.
\end{abstract}

Keywords: historical descriptive; diffusion; energy technologies; mobile phones. 


\section{Calling for Change? Innovation, diffusion, and the energy impacts of global mobile telephony}

\section{Introduction}

The success of mobile communication over the past thirty years has had important consequences in people's daily lives at the global scale. This is an example of a relatively fast diffusion process in - enduse - energy technologies (Sovacool, 2016). The number of mobile phone subscriptions worldwide was estimated at 6.9 billion in 2013 (ITU, 2014) - the number of unique mobile users is more difficult to estimate, since one user may own multiple subscriptions (Annafari \& Bohlin, 2014) and one subscription can be shared by several individuals (e.g. in Africa); even so market surveys have reported figures well above 4 billion people (Ericcson, 2014). The growth of cellular networks was so spectacular that it outpaced the dissemination of electricity to the point that millions must travel significant distances and pay an astronomical premium to charge their handsets in energy kiosks (Kemeny et al., 2014). ${ }^{1}$ Changes in social practices in charging and managing the power have been identified even in developed countries (Horta et al., 2016). This situation draws attention to the power needs of the apparently low energy consumption handsets, but whose use is rapidly growing namely in developing countries.

This study examines three decades of diffusion of cellular phones from the early networks in Scandinavia to the present, with particular regard for the dynamics of growth and its implications in terms of energy demand. Existing studies of mobile phones growth apply standard epidemic models (e.g. Chang, Li, \& Kim, 2014; Riikonen et al., 2013; Kauffman \& Techatassanasoontorn, 2009; Singh, 2008; Rouvinen, 2006; Jang, Dai, \& Sung, 2005; Liikanen, Stoneman, \& Toivanen, 2004; Botelho, Pinto, 2004; Gruber \& Verboren, 2001) often used in the empirical literature of technology diffusion. ${ }^{2}$ This paper particularly uses the logistic model which has been shown to generate the most accurate forecasts for mobile telephony growth (Meade \& Islam, 2015). This work advances over the previous investigations both in scope and approach of the analysis.

First, the use of data on the number of users in more than 200 countries between 1980 and 2010 provides a more complete picture of the diffusion of cellphones. Second, the estimation of the energy

\footnotetext{
${ }^{1}$ It has been reported that in cites kiosks in Papua New Guinea customers pay for each bar of charge shown on the phone's display at a cost equivalent to $\$ 200$ per $\mathrm{kWh}$ (The Economist, 2015).

2 The following works have played an important role in the definition of epidemic models: Griliches (1957); Bain (1956); and Bass (1969). For a review of diffusion models see Geroski (2000) and Stoneman (2002).
} 
needs of the handsets reveals additional information about the repercussions of telecommunication in other sectors. This extends earlier attempts to estimate the energy consumption of mobile phone use (Paiano, Lagioia, \& Cataldo, 2013; Sadordsky, 2012; Schaefer, Weber, \& Voss, 2003), including in lifecycle assessments (Malmodin et al., 2010; Yu, Williams, \& Ju, 2010; Scharnhorst, Hilty, \& Jolliet, 2006), almost always performed at a country level. Finally, the systemic analysis of market and power consumption trends provides valuable insights about the impact of mobile communication on energy consumption and, thus, on sustainability.

This analysis deals with important questions in the crossroads of energy research and social sciences (Sovacool, 2014). The object of study has an egalitarian (including gender) and empowering character which is improving the standard of living in poor areas of the world. In addition, the analysis is historical and systemic that draws on disciplines such as science and technology studies, electrical engineering, marketing science and economics, responding to the calls for the use of a more interdisciplinary approach to enrich the explanatory power of social science researches. Finally, the examination of the factors of fast diffusion of small scale, more "granular", energy technologies like cellphones raise important questions about the relationship between technology scale and speed of diffusion that are particularly important for the definition of technology policy.

Therefore, this research addresses the following questions: What is the trend in the production and use of mobile phones? What are the energy needs of mobile telecommunication, namely in relation to other technologies? More than a straight forward application of extrapolation using logistic curves, this research analyzes diffusion patterns at both global and regional scales, as well as the likely impacts on the energy system.

The paper is structured as follows. Firstly, the extent of the mobile phone diffusion is analyzed together with the determinants of growth found in the literature. Secondly, the methodological issues and data sources are explained. Thirdly, the results of the analysis of the growth of mobile phones, as well as their energy needs, are presented. Finally, the main conclusions are discussed in terms of the characteristics of diffusion and the direct effects in energy consumption, drawing some implications for policy namely in rapidly growing markets in developing countries. 


\section{Historical growth and extent}

Cellular phones constitute the largest electronic market, having undergone an explosive diffusion over the past two decades, with annual sales stabilizing around 1.7 billion devices in 2010-2012 (Gartner, 2013). ${ }^{3}$ In 2012 there were over 400 million shipments per quarter, almost as much as the number of devices sold seven years before (In-Stat/MDR, 2004).

The historical growth of mobile phone subscriptions is marked by gradual dissemination across countries. Figure 1 shows the evolution of subscriptions in six selected regions: three pioneer areas (Scandinavian countries, Japan and United States), as well as in three other countries that became quite influential (China and India for the absolute number of subscriptions and the Republic of Korea for the relatively high ownership). Figure 2 shows the growth of the number of subscriptions, globally.

Four phases can be identified in the analysis of the process of spatial diffusion of mobile phones across countries: i) in the late 1970s mobile phones first penetrated the market in Scandinavia and Japan; ii) in the second half of the 1980s they entered in the US with a delay of some years, since then the growth was very intensive there; iii) in the 1990s the diffusion accelerated worldwide due to the growth in developed countries, such as China and India; and iv) after the year 2000 growth stabilized in developed countries, while global subscriptions kept growing, pushed by the diffusion in developing countries. The worldwide growth is now being led by China and India, with 1.1 billion and 865 million subscriptions in 2012 respectively, compared to 310 million in the US by that time (ITU, 2013). Republic of Korea presents a very high mobile penetration with more than 1.1 subscriptions per capita, half of which were already 4G LTE in 2013 - the highest rate in the world (Ericsson, 2014).

\footnotetext{
${ }^{3}$ For a complete overview of global statistics on mobile phones, see: http://mobiforge.com/research-analysis/globalmobile-statistics-2014-home-all-latest-stats-mobile-web-apps-marketing-advertising-subscriber (last accessed in May 30, 2015).
} 

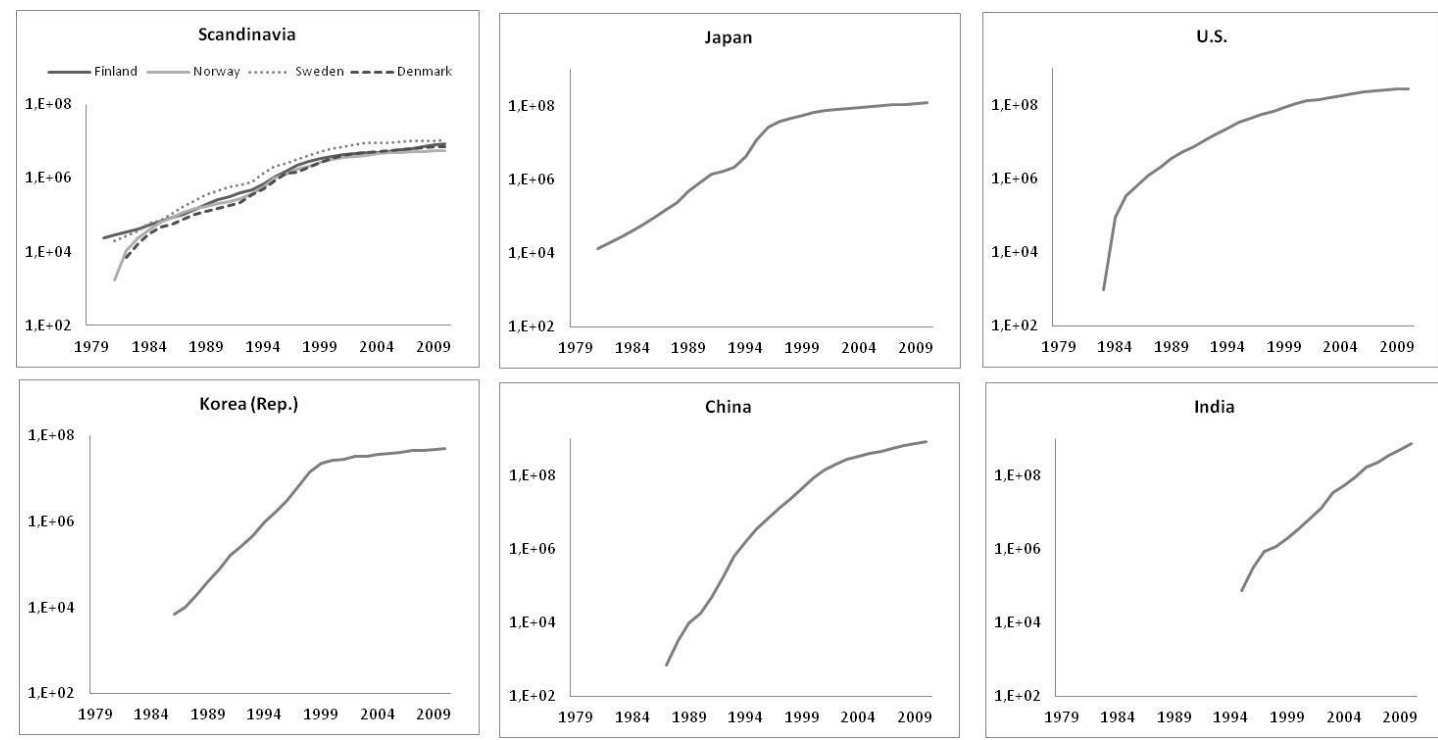

Fig. 1. The evolution of mobile phone subscriptions in selected regions (semi-log axis). Data source: ITU World Telecommunication (ITU, 2011, 2013).

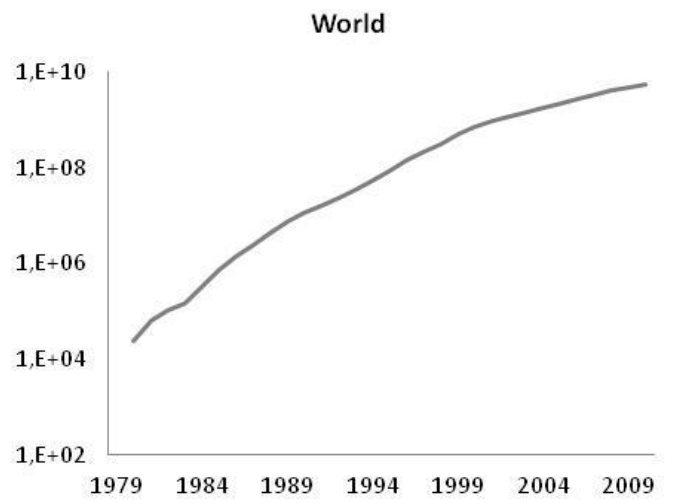

Fig. 2. The evolution of mobile phone subscriptions globally (semi-log axis). Data source: ITU World Telecommunication (ITU, 2011, 2013).

The extent of the diffusion of mobile phones can be assessed in comparison with other popular goods, such as radio sets or bicycles. The Lorenz curve was originally developed as an indicator of inequality in the income or wealth distribution, though it can also measure the disparity in the distribution of goods 
(Gastwirth, 1972). ${ }^{4}$ Figure 3 presents a Lorenz curve measuring the inequality of cell phone subscriptions for a group of 27 countries (including developed and developing nations), covering roughly $60 \%$ of the world population. An interesting finding is that mobile phones have recently become the most popular technology, surpassing radio sets. In fact mobile phones present the lowest Gini coefficient (13.83\%) compared to bicycles (39.7\%) and radio sets (49.1\%) - the higher the coefficient, the more unequal the distribution. The Lorenz curve clearly illustrates that cellphones are evenly distributed compared to other technologies, what is an indicator of the importance these devices have for the world today.

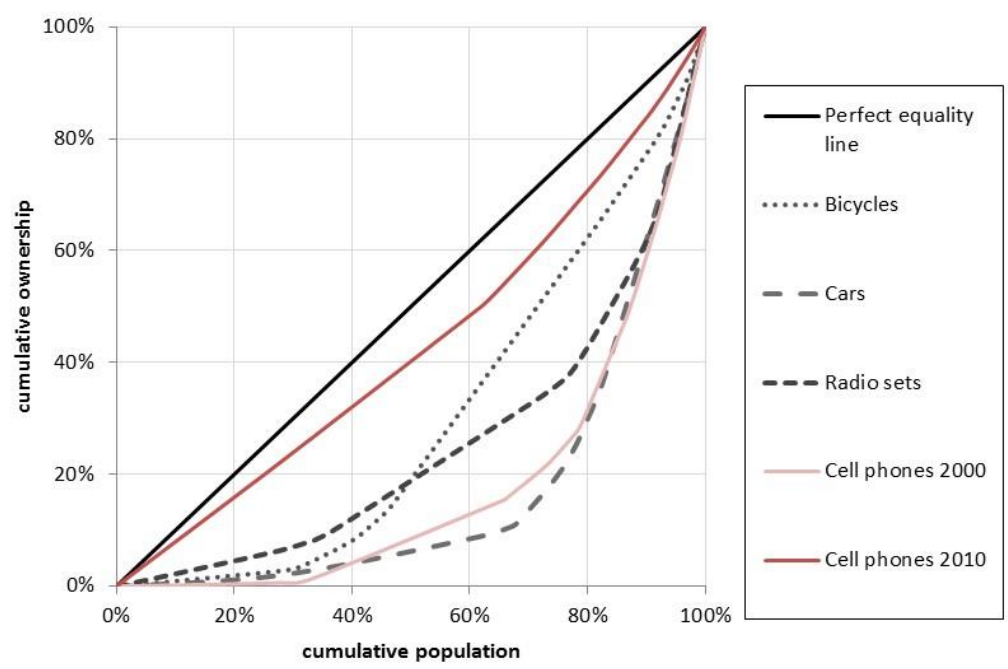

Fig. 3. Lorenz curves for different technologies in late 2000s. Data Sources: [Bicycles] (Bicycle Retailer and Industry News, 1998; BOVAG-RAI, 2008); [Cars] (World Bank, 2011); [Motorcycles] (BOVAG-RAI, 2008; JAMA, 2011; U.S. Census Bureau, 2010); [Radio sets] (ITU, 2011); [Population] (UN Population Division, 2011). Population data for 2005 (except for Australia, Argentina, Brazil and Switzerland: 1995). ${ }^{5}$

In the last ten years there was an enormous evolution in the access to mobile communication. The disparity in the ownership of mobile phones has been reduced with the increasing use of cellular phones in countries with the lowest incomes. The Gini index passed from $63.5 \%$ in 2000 to $13.83 \%$ ten years

\footnotetext{
${ }^{4}$ Radio sets were long considered the most popular technology, bicycles are the most democratic transport in use worldwide (Bento, 2012), and cars were chosen because of their importance for transportation in many countries.

${ }^{5}$ Firstly the ownership of assets was calculated by country, and then the countries were sorted out in ascending order of the number of assets per 1,000 people. A point in the curve means that X\% of the people owns $\mathrm{Y} \%$ of the total number of goods, irrespective of their nationality. In a completely unequal world all the goods are owned by the last person and everyone else has none, while in a perfectly equal world every person would have the same share of the income or goods. The latter situation serves as the benchmark for the asset distribution and is represented by the straight line " $y "=$ " $x "$ ", called the "perfect equality line". The Gini coefficient is an indicator of inequality which compares the area between perfect equality and the observed Lorenz curve with the area below the perfect equality line. The higher the coefficient, the more unequal the distribution is compared to an ideal world. Hence a low Gini coefficient indicates a more equal distribution, with 0 corresponding to complete equality, while higher Gini coefficients point to more unequal distribution, with 1 corresponding to complete inequality.
} 
later (Figure 3), thus demonstrating that mobile phones have had an enormous impact in almost all subgroups of the population. This was possible because the costs did not inhibit the expansion of demand, especially in low-income countries. The next section reviews this and other factors that have played a significant role in diffusion.

\section{Determinants of diffusion: A review}

A consolidated literature analyzes the main factors that influenced the growth of mobile communication (e.g. Bohlin, Gruber, \& Koutroumpis, 2010; Grajek \& Kretschmer, 2009; Jang et al., 2005; Liikanen et al., 2004; Gruber \& Verboren, 2001). These factors include the role of low prices, technology development, rapid standardization, network effects, and previous existence of the fixed-line telephony.

Firstly, the decreasing price of handsets and communication services has been a decisive factor for the success of cellphones. Table 1 shows the prices (discounted by the inflation) at which highly sold handsets were launched in a particular country (United States). In fact, feature phones are currently priced at around $1 \%$ of the original price of the Motorola DynaTAC 8000x (first commercial mobile phone) three decades ago. Smartphones are more expensive - here approached by the price of successful, though high range, Apple iPhones - but their real prices have also been decreasing since their introduction into the market. ${ }^{6}$

The cost of communication services has followed the same trend of the handsets price. The transition from the analogue to the digital technology in Europe in the 1990s prompted operators to reduce service prices in order to attract new customers (Gruber \& Verboren, 2001). The implementation of the GSM standard (2G) was followed by the promotion of competition and the attribution of additional licenses for mobile communication services, contributing to further price decreases (Jang et al., 2005; Gruber \& Verboren, 2001). In a study on 2G adoption in 41 countries between 1998 and 2004, it was found a correlation between decreasing cellular service costs and increasing phone usage (Grajek \& Kretschmer, 2009). As a consequence, the price of the equipment and cellular service is becoming less a barrier to diffusion namely in low income countries.

\footnotetext{
${ }^{6}$ Even Apple has recently announced plans to launch a cheaper version of the iPhone. Although with an expected cost around $\$ 400$, this cheaper version will still be priced twice as much as the low cost of the market (Financial Times, 2016).
} 


\begin{tabular}{|c|c|c|c|c|c|}
\hline \multirow[t]{2}{*}{ Model } & \multirow[t]{2}{*}{ Release year } & \multirow{2}{*}{$\begin{array}{l}\text { Units sold } \\
\text { [millions] }\end{array}$} & \multicolumn{3}{|c|}{ Launch price (in US) } \\
\hline & & & $\begin{array}{c}\text { Current price } \\
\text { [US\$] }\end{array}$ & $\begin{array}{l}\text { Constant price } \\
\text { [in } 2014 \text { US\$] }\end{array}$ & $\begin{array}{l}\text { Const. price index } \\
\text { [DynaTAC }=100]\end{array}$ \\
\hline \multicolumn{6}{|l|}{ Feature phones } \\
\hline Motorola DynaTAC 8000x & 1983 & n.a. & 3995 & 9496 & 100 \\
\hline NEC P3 & 1990 & n.a. & 1990 & 3604 & 38 \\
\hline Motorola StarTAC & 1996 & 60 & 1000 & 1509 & 16 \\
\hline Siemens A50 & 2002 & 15 & 100 & 132 & 1 \\
\hline Nokia 1100 & 2003 & 250 & 110 & 142 & 1 \\
\hline Motorola RAR V3 & 2004 & 130 & 300 & 376 & 4 \\
\hline Samsung E1100 & 2009 & 150 & 69 & 76 & 1 \\
\hline \multicolumn{6}{|l|}{ Smartphones } \\
\hline Apple 1 & 2007 & 7 & 600 & 685 & 7 \\
\hline Apple 5 & 2012 & 70 & 600 & 619 & 7 \\
\hline
\end{tabular}

n.a. - not available.

Table 1. Launch prices of selected mobile phones in the United States. Original and CPI-adjusted prices. Information compiled by the author from news published in the press, manufacturers' catalogues and dedicated review websites (e.g. www.gsmarena.com).

Secondly, the successive improvements in cellphones have reinforced their attractiveness. The first technology available to consumers in the 1980 s was based on analogue signal transmission, which had a limited capacity and a low quality of service. ${ }^{7}$ The essential technology improvement occurred after the 1990s with the gradual transition from the first generation analogue $(1 \mathrm{G})$ to the digital technology (second-generation, 2G). Digital technology could accommodate more users within the network and still provide a reliable and better quality of service (Gruber \& Verboren, 2001). It also featured SMS functionality which turned to be a great success among young users, especially in Asia and Europe (Grajek \& Kretschmer, 2009; Watanabe, Moriyama \& Shin, 2009). The subsequent third (3G) and more recently fourth generation (4G) have further improved data transmission, enabling new functionalities such as internet connection and email service (Hilbert \& López, 2012, 2011), what contributed to sustain demand.

Thirdly, the establishment of common standards and international protocols was crucial for the rapid diffusion of mobile communication by allowing the full exploitation of network externalities (Liikanen et al., 2004; Yoo, Lyytinen, \& Yang, 2005). A number of technological standards co-existed within the same generation and even countries, especially in the first two decades (Liikanen et al., 2004). In spite of the

\footnotetext{
${ }^{7}$ The recent history of technological improvements and subsequent generation changes is presented in more detail in Gruber and Verboren (2001), Grajek and Kretschmer (2009) and Bohlin, Gruber, and Koutroumpis (2010).
} 
leading role that the US played in the invention of mobile telecommunication, diffusion starts first in Scandinavia. ${ }^{8}$ This was the result of the delay taken in licensing and in the establishment of common standards in the former (Hausman, 1997). Conversely, several European countries coordinated the adoption of the digital standard GSM (2G) in the 80s, well in advance of its first implementation in Finland in 1991 (Liikanen et al., 2004). ${ }^{9}$ This contributed to the faster diffusion of cellular telecommunication in Europe comparing with other countries.

Similarly, the standardization enabled learning gains and a rapid enlargement of the initial number of users, increasing the benefits to buy a new handset through the communication with a larger share of people (Katz \& Shapiro, 1985; Liebowitz \& Margolis, 2000; Economides, 1996). This explains the logistic pattern of growth, i.e., cellphones diffused very rapidly once a given threshold of users was reached (Shapiro \& Varian, 1998; Arthur, 1989; David, 1985). Empirical studies confirm that network effects have significantly contributed to accelerate the rate of mobile phone diffusion (Gruber \& Verboren, 2001; Liikanen et al., 2004; Grajek \& Kretschmer, 2009; Watanabe et al., 2009, 2004).

Finally, the fixed-line telephony helped cellular phones overcome the start-up problem by allowing communication with "fixed" users. Grajek \& Kretschmer (2009) found that the complementary effect in terms of usage can dominate at the start of the diffusion of cellular telecommunication. However, the installed base of the old technology may also prevent the switch to the new technology (Farrell \& Saloner, 1985). Figure 4 shows that the growth of mobile phones is concomitant with the reduction in the number of fixed telephone subscriptions. As the evidence suggests, cellphone's subscriptions is gradually replacing landline communication almost everywhere in the world. This substitution effect has been confirmed by previous econometric studies (Liikanen et al., 2004; Gruber \& Verboren, 2001).

\footnotetext{
${ }^{8}$ The first mobile telecommunication systems appeared in the 1940s in the US and in Scandinavia in the 1970s. The telephones were so heavy and large that had to be installed in vehicles. In addition, calls were manually switched, instead of automatic dialing, what made them a predecessor of cellular communication technology rather than a part of it, as pointed by Liikanen et al., 2004.

${ }^{9}$ Liikanen et al. (2004) surveyed the network effects within and between different generations of mobile telecommunication technologies, particularly the analog technology (1G) and the digital technology (2G). The authors had undergone an econometric analysis of the diffusion model parameters using data from 80 countries between 1991 and 1998. It was found that the network effects are larger within the same technology generation and the diffusion of $1 \mathrm{G}$ had a positive effect in the dissemination of the $2 \mathrm{G}$. Bohlin, Gruber, \& Koutroumpis (2010) corroborates the latter result, but find that adoption of $2 \mathrm{G}$ negatively affected the adoption of $3 \mathrm{G}$.
} 


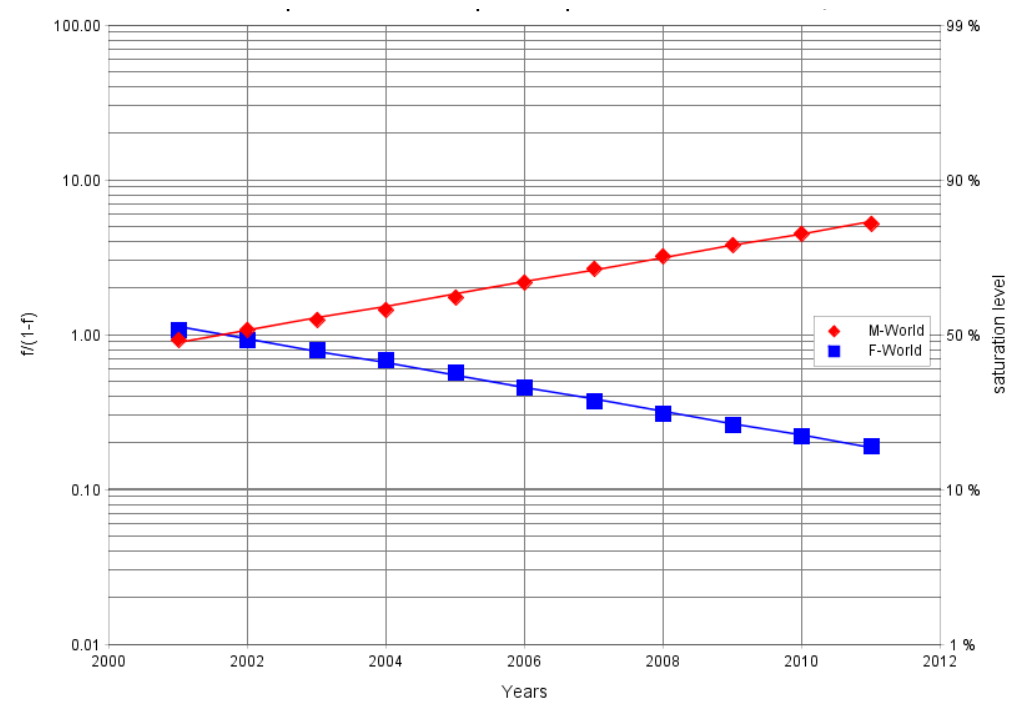

Fig. 4. The number of fixed telephone and mobile phone subscriptions per 100 inhabitants between 2000 and 2010 . The graph is plotted accordingly to the logit transform. The division of the market share (F) by the remaining share (1-F) yields a straight line when plotted on a logarithmic scale (cf. Fisher \& Pry, 1971). Data source: ITU World Telecommunication (ITU, 2011).

In conclusion, the rapid penetration of mobile phones has been possible thanks to affordable prices, technological improvements, rapid standardization, network externalities, and the existence of an installed base of the previous technology (fixed-line). Nevertheless, the success of mobile phones is also the result of important processes that occurred at social level. Ling (2004) studies the interaction between technology and society to understand the social impacts and factors of cellphones use. The author suggests a compromise perspective between technological determinism and Beijker \& Law (1992) social determinism, called "domestication". Hence, mobile phones successfully incorporate into society in several predictable steps (imagination, appropriation, objectification, incorporation, conversion). This sociological perspective unveils the importance of other factors in the widespread adoption of mobile phones, from safety and "micro-coordination" of everyday life for older people until pricing (e.g. "pay as you go' subscriptions and cheap text messaging) and developing social networks for younger people. 


\section{Methodological issues}

\subsection{Diffusion model}

This investigation aims to examine the trend in the production and use of mobile phones and the effect in energy demand. The research mainly uses logistic growth models to fit actual data in order to identify patterns in the historical diffusion of mobile phones. There is a wide range of evidence derived from extensive studies of the diffusion of new technologies supporting the use of the three-parameter logistic function (Grubler, 1998; Marchetti \& Nakicenovic, 1979; Modis, 2002). Specifically in the context of mobile communication, Meade and Islam (2015) compares forecasts of the number of subscriptions for 25 countries against actual data and conclude that the most accurate forecasts fitted a logistic to adoption data. The logistic function is generally inspired by the logistic model (Fisher \& Pry, 1971)-a Sshaped model assuming symmetry around the inflection point-representing technological diffusion as follows:

$y(t)=\frac{K}{1+\exp \left(-b\left(t-t_{0}\right)\right)}$

The logistic function provides information about the extension and the speed of diffusion. The parameter $K$ gives the saturation level of diffusion, while the parameter $b$ allows to estimate the deltaT (or $\Delta t$, through the relation $\Delta t=(1 / b) \cdot \log 81)$. This is a measure of the time duration of diffusion-more precisely, from $10 \%$ to $90 \%$ of saturation - which is inversely proportional to the rate of diffusion, with higher $\Delta t$ values meaning slower diffusion. And $t_{0}$ gives the inflection point reached at $50 \%$ of saturation. The use of those parameters is subject to criteria of accuracy (minimum $R^{2}=95 \%$ ) and reliability (minimum $60 \%$ of estimated asymptote covered by actual data) following Debecker and Modis (1994).

The procedure consists of fitting a logistic curve to variable $y$ which represents the production, the energy capacity (in MW) or the energy consumption (in MWh). Growth at industry level is investigated in terms of total cumulative unit numbers, and converted into cumulative capacity using the average capacity of phones. Cumulative figures better express the entire history of production. The average and the maximum size (or capacity) of cellphones were found in the field trials reported below (see Appendix 1) and validated through comparison with the values found in the literature. In turn, the evolution of demand for mobile phones is analyzed in terms of the number of subscriptions, as well as the estimates of the capacity installed and energy consumption of the cellphones in use, following the 
same procedure for fitting as in the case of production, except that current figures are used instead of cumulative numbers in order to better identify trends in use.

In the cases where diffusion does not quite follow a standard logistic pattern, further testing is carried out to ascertain whether the ultimate potential for growth has been modified over time. Some innovations expand their saturation levels over the course of the diffusion process. Meyer (1994) presents several technology systems that experienced two logistic growth "pulses" (simultaneously or sequentially), for which bi-logistic functions are more adequate to model such complex growth processes. Meyer and Ausubel (1999), more generally, examine the growth of technologies that dynamically enlarged the limits of diffusion. They propose an extension of the logistic growth model that allows for a sigmoidally expanding carrying capacity (i.e. saturation). Watanabe et al. $(2004,2009)$ apply this function to model the diffusion of several technologies in Japan, finding that cellular phones particularly demonstrate a self-propagating behavior - with increasing levels of carrying capacity arguably pushed by network externalities and functionality development. Therefore, these two complex epidemic functions (bi-logistic function and logistic growth function within a dynamic carrying capacity, respectively) were also used to describe the diffusion processes:

$$
\begin{aligned}
& y(t)=y_{1}(t)+y_{2}(t)=\frac{K_{1}}{1+\exp \left(-b_{1}\left(t-t_{0_{1}}\right)\right)}+\frac{K_{2}}{1+\exp \left(-b_{2}\left(t-t_{0_{2}}\right)\right)} \\
& y(t)=\frac{K_{k}}{1+\exp \left(-b\left(t-t_{o}\right)\right)+\frac{b}{b-b_{k}} \exp \left(-b_{k}\left(t-t_{0_{k}}\right)\right)},
\end{aligned}
$$

given logistically varying limits $K(t)=\frac{\mathrm{K}_{t}}{1+\exp \left(-b_{k}\left(t-t_{0_{k}}\right)\right)}$

\subsection{Data sources}

The study is based on annual data and covers more than 200 countries for the period 1980-2010. The data on the number of subscriptions at the end of each year comes from the International Telecommunication Union (ITU) and its database available online (ITU, 2014). Numbers on handsets' production are more difficult to find and less reliable than on subscribers. We used publically available data on cellular phones shipments from private consulting companies (Gartner - press releases (various years); In-Stat/MDR, 2004) specialized in information technology. It was assumed that all the phones 
were produced and sold within the same year. This assumption is unlikely to affect the results since we are looking at the diffusion in the long-term. There is data available for the last decade, when the number of handsets sold was the highest. For preceding years, production was estimated by interpolation of both the market share of each region and the total annual number of devices produced globally.

The long-term trends in performance and energy use of mobile phones were investigated through the construction of a database that compiles information in several dimensions, such as physical characteristics and autonomy, for more than a hundred handsets among the best-selling models of all time. This information was collected from publically available documents, e.g. product catalogues, manufacturer's websites, articles in the press, and specialized websites (e.g. www.gsmare.com). Concerning the real power capacity and energy consumption of mobile phones, which are necessary to calculate the equivalent installed capacity of phones and their energy consumption, a field trial was organized to estimate the average consumption of the devices (see point 5.2. and Appendix 1).

\section{Results}

This section starts by examining the diffusion patterns of mobile phones and then studies the evolution of the energy use by handsets to estimate the overall impact on energy demand. Finally, the duration and extent of mobile phones growth is assessed by comparing their trends with those of other energy technologies.

\subsection{Current trends in adoption}

This section aims to identify key patterns and trends of the development of mobile phones. The number of subscriptions per 1,000 people is used as a proxy of the number of mobile phones in use. In order to be operational, the cell phone's user must subscribe to a contract with a network provider (normally via the acquisition of a SIM card). ${ }^{10}$

\footnotetext{
10 The number of subscriptions is used as the first approximation to the real number of users, for which no data is available. It is nevertheless acknowledged that this may be an overestimate of the exact number of users, as people can use more than one cell phone (Annafari \& Bohlin, 2014). However, it is not likely to affect the accuracy of the scale of the number of users. The reliability of the data was ensured by performing a cross-check evaluation with the number of handsets produced and realistic assumptions for their expected lifetime (1.5-3 years). Empirical studies on
} 
Figure 5 and Table 2 present the diffusion of mobile phone subscriptions by region (defined according to the sequence of diffusion described in section 2) and the logistic fits. The evolution of global subscriptions is impressive reaching 5.4 billion in 2010, with a market potential estimated at more than one contract per capita. The penetration of mobile phones is attaining saturation in both Core and Rim at 1.3 subscriptions per capita, while it has some potential of growth in the other areas. The current value in the Periphery is around 0.8 contracts per capita, still far from saturation, which was estimated around 1.2 subscriptions per capita. These numbers confirm the enormous success of mobile phones in attaining a large share of the global population.

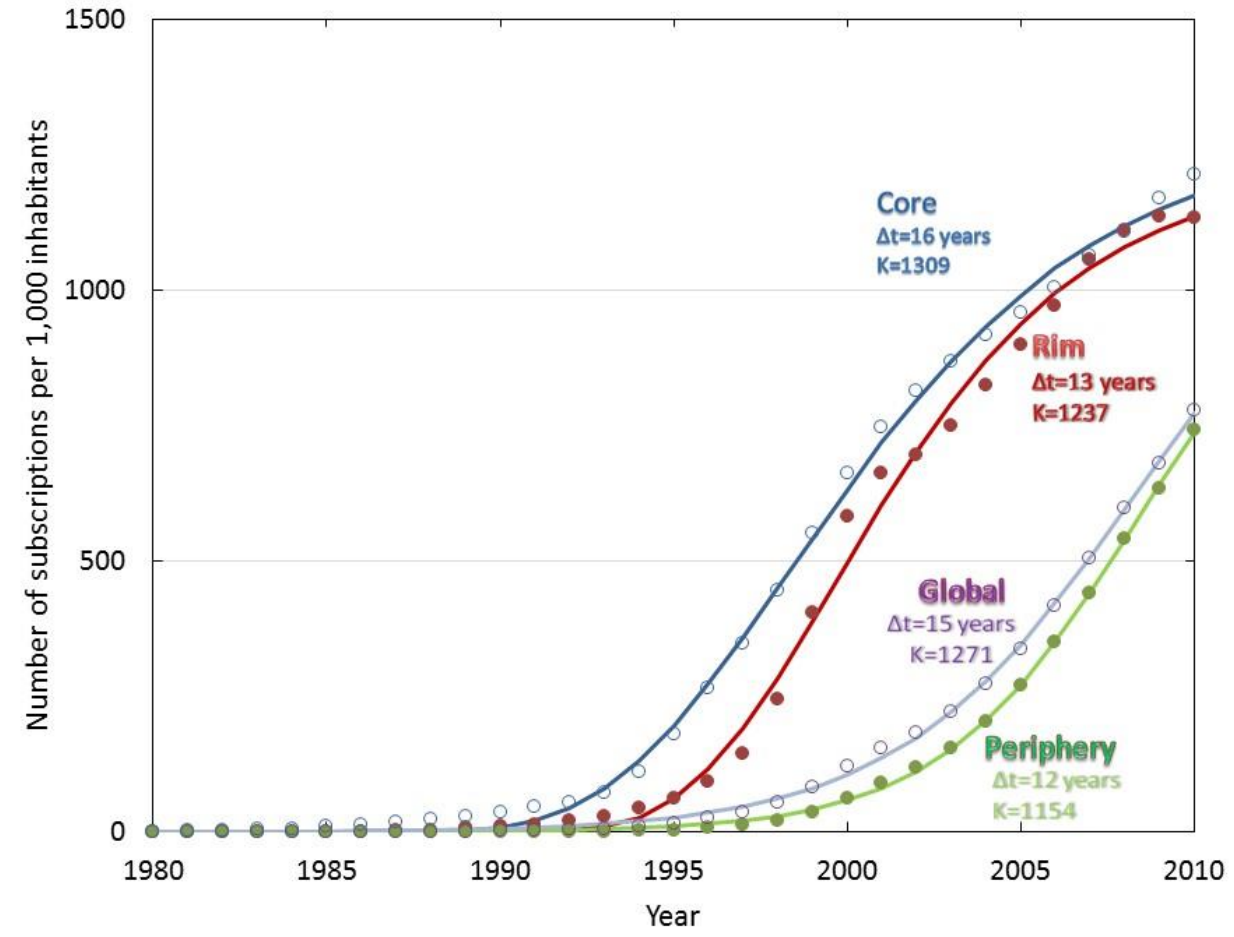

Fig. 5. The growth of mobile phone subscriptions and logistic fits (dashed lines) between 1980 and 2010. The countries are separated into three main regions according to the order of diffusion by region, between: Core consisting of the Scandinavian countries (i.e., Finland, Norway, Sweden and Denmark), and Japan; RIM including the U.S., the Netherlands, Germany, France, Italy, the United Kingdom, Canada, Austria, and Korea Republic; and Periphery constituted by the rest of the world. Both growth in Core and Rim are better fitted with Gompertz curves. Data source: ITU (2011); UN Population Division (2011).

'replacement cycles' reported a recent evolution from 23 months (one year and 11 months) to 27 months (two years and three months) (Financial Times, 2016). 


\begin{tabular}{lccccc}
\hline Region & Actual \% & $\boldsymbol{K}$ & $\boldsymbol{t}_{\boldsymbol{0}}$ & $\boldsymbol{\Delta t}$ & $\boldsymbol{R}^{\mathbf{2}}$ \\
\hline Core & $93 \%$ & 1309 & 1998 & 16.1 & $99.84 \%$ \\
Rim & $92 \%$ & 1237 & 2000 & 12.9 & $99.27 \%$ \\
Periphery & $64 \%$ & 1154 & 2008 & 12.6 & $99.96 \%$ \\
Global & $61 \%$ & 1271 & 2008 & 15.4 & $99.97 \%$ \\
\hline
\end{tabular}

Table 2. Parameters of the fit curves. Gompertz curves are used in Core and Rim instead of logistics as they best fit actual growth. The $\mathrm{R}^{2}$ is always superior to $95 \%$ as required by the accuracy criteria (see in methodology).

The diffusion process in Core and Rim is better fitted by a Gompertz curve, an epidemic function which does not require symmetry around the inflection point conversely to the standard logistic growth model. If this pattern can be explained by the gradual spatial diffusion of mobile phones in fast follower countries in the Rim area, it requires further analysis with more complex models in the Core.

Table 3 compares the parameters of the three logistic functions for the diffusion process of mobile phones in the Core, as well as the respective adjusted $R^{2}\left(A j d . R^{2}\right)$ and the Akaike Information Criterion corrected for the small size of the sample in comparison with the number of parameters (AICc). Bilogistic growth is clearly the most adequate epidemic function to grasp the trends of the diffusion process in the Core (higher Ajd. $R^{2}$ and lower AICc). The quality of the fit and the results of the parameters are illustrated in Fig.6.

\begin{tabular}{|c|c|c|c|c|c|c|c|c|c|c|}
\hline Logistic functions & $K$ & to & $\Delta t$ & $b$ & & & & & Adj. $R^{2}$ & $A I C c$ \\
\hline $\begin{array}{l}\text { 1) Simple logistic } \\
\text { growth }\end{array}$ & 1177 & 2000 & 12.98 & 0.339 & & & & & $99.62 \%$ & 214 \\
\hline & $K_{1}$ & to 1 & $\Delta t_{1}$ & $b_{1}$ & $K_{2}$ & $t_{2}$ & $\Delta t_{2}$ & $b_{2}$ & $\operatorname{Adj.} R^{2}$ & $A I C c$ \\
\hline $\begin{array}{l}\text { 2) Bi-logistic } \\
\text { growth }\end{array}$ & 1011 & 1999 & 10.37 & 0.424 & 313 & 2009 & 7.84 & 0.56 & $99.96 \%$ & 149 \\
\hline & $K_{k}$ & to & $\Delta t$ & $b$ & $t o_{k}$ & $\Delta t_{k}$ & $b_{k}$ & & $\operatorname{Adj} . R^{2}$ & $A I C c$ \\
\hline $\begin{array}{l}\text { 3) Logistic growth } \\
\text { with logistically } \\
\text { varying limits }\end{array}$ & 1400 & 1999 & 9.96 & 0.441 & 1994 & 35.05 & .125 & & $99.84 \%$ & 187 \\
\hline
\end{tabular}

Table 3. Comparison of the fit of three logistic functions for the diffusion of mobile phones in the Core.

\footnotetext{
${ }^{11}$ In order to facilitate the estimation of the three parameters ( $K$, to and $\Delta \mathrm{t}$ ), equations can be further simplified. By setting $\exp \left(-b t_{0}\right)=a$, we retrieve the following logistic functions:
} 


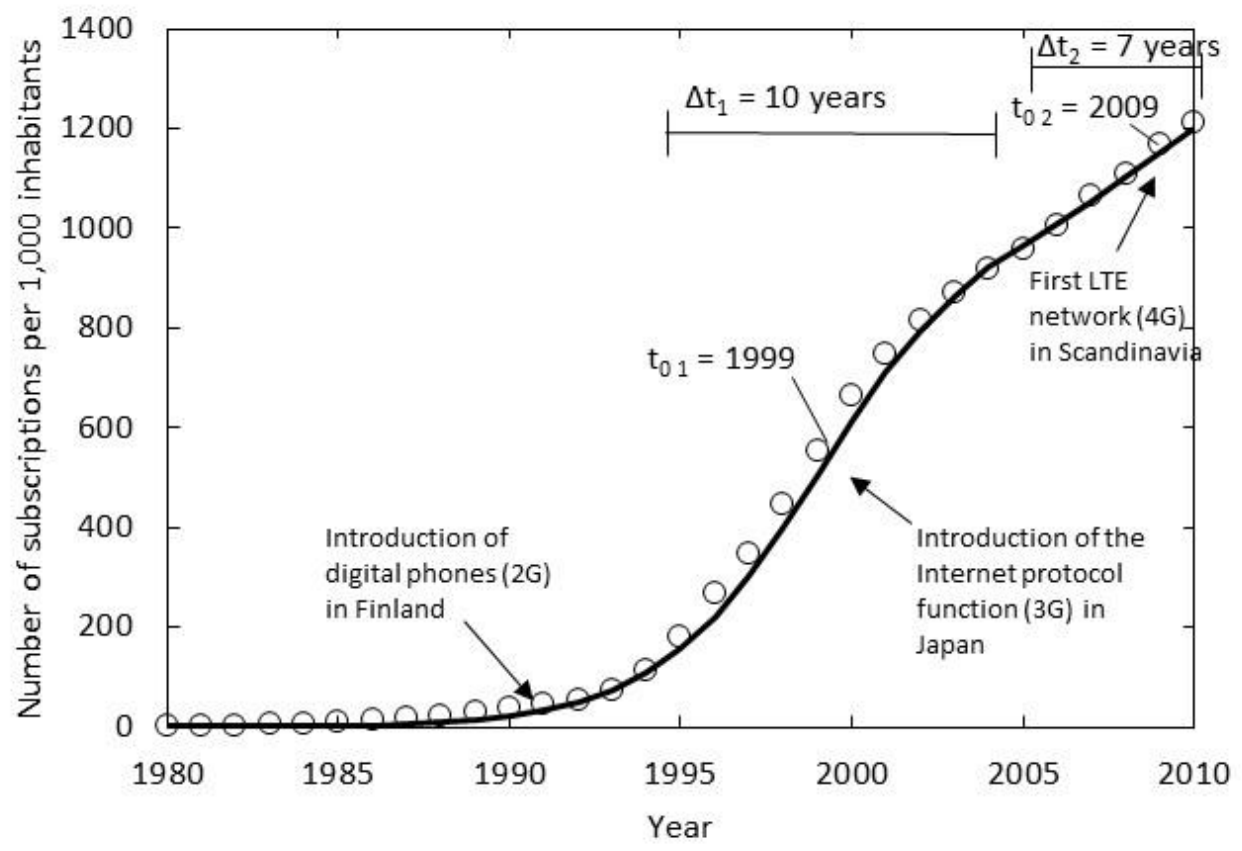

-Bi-logistic $\bigcirc$ Actual

Fig. 6. The growth of mobile phone subscriptions in Core between 1980 and 2010: actual data and estimate according to the bi-logistic fit.

Looking at Fig.6, it is possible to note that the growth in the adoption of mobile phones knows two logistic pulses of 10 years $\left(\Delta t_{1}\right)$ and 7 years $\left(\Delta t_{2}\right)$, respectively. The take-off of the first "pulse" follows the introduction of digital phones $(2 \mathrm{G})$, while the inflection point $\left(t_{0_{1}}\right)$ coincides with the start of the first $3 \mathrm{G}$ networks (in Japan) that enable internet access in the handsets. The development of mobile internet connection supported the remaining growth of the first wave, eventually launching the seeds for the second wave of growth. This seems to be corroborated by the analysis of the statistics of active mobilebroadband subscriptions in developed countries (Fig. 7). Finally, the first commercial launch of the $4 G$

1) Simple logistic growth: $y(t)=\frac{K}{1+a \exp (-b t)}$

2) Bi-logistic growth: $y(t)=y_{1}(t)+y_{2}(t)=\frac{K_{1}}{1+a_{1} \exp \left(-b_{1} t\right)}+\frac{K_{2}}{1+a_{2} \exp \left(-b_{2} t\right)}$

3) Logistic growth with logistically varying limits: $y(t)=\frac{K_{k}}{1+\mathrm{a} \exp (-b t)+\frac{b a_{k}}{b-b_{k}} \exp \left(-b_{k} t\right)}$ 
coincides with the inflection point $\left(t_{0_{2}}\right)$ of the second growth pulse, which may sustain the growth in the number of subscriptions during the next years.

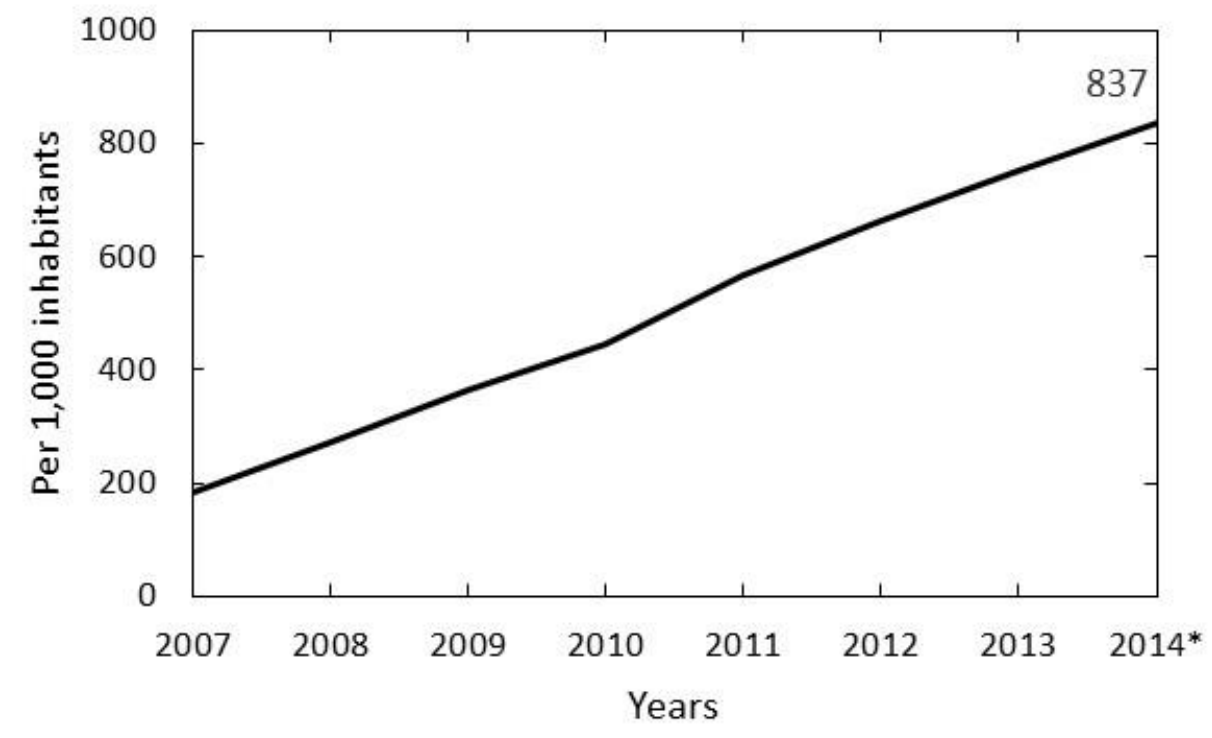

Fig. 7. Active mobile-broadband subscriptions per 1,000 inhabitants, in developed countries, between 2007 and 2014 . Note: * Estimate. The developed country classification is based on the UN M49. Data source: ITU World Telecommunication /ICT Indicators database, 2014.

\subsection{Estimation of energy power and needs of mobile phones}

The energy consumption of a handset is in the range of a few Watts, but what is the impact of billions of cell phones in operation at the same time? The energy requirements at unit level are first assessed through the analysis of the trends in energy efficiency of handsets and the examination of their energy usage with the help of a field trial. The results are then combined with the values for demand estimated in section 5.1. in order to assess the extent of growth of the installed capacity and of the energy consumption in the following sections.

\subsubsection{Trends in size, functionality and energy efficiency}

The historical evolution of mobile phones is analyzed through a survey of the characteristics of a sample of 101 handsets (90 feature phones and 11 smartphones) in several dimensions: size, weight, autonomy, functionality, and energy efficiency. To ensure that the sample is representative, the models were 
chosen from lists of the top-selling handsets of all time. These lists have been published separately by market intelligence companies (e.g. IDC, Gartner) and compiled by sites specialized in mobile communication, such as mobiForge. ${ }^{12}$ All data included in the analysis is taken from product technical information provided by the manufacturers.

The models show a remarkable evolution in size and autonomy over time. Since the first commercial model (Motorola DynaTAC 8000x) in 1983, handsets have gotten smaller and become one-seventh of their original size (Fig.8), with a tenth of the weight (not shown). Dimensions can vary, depending on manufacturers and types. For example, smartphones are slightly bigger and heavier than feature phones, but this does not alter the industry's general response towards satisfying customer preferences for a slim design and lighter weight.

The energy storage capacity of the handsets has, however, remained almost the same over time - often around 500-1000 mAh (Fig.9) - thanks to the adoption of less cumbersome and more efficient batteries. In fact, most of the handsets in the sample released after 2000 are equipped with Li-lon-types of batteries which are more expensive than similar capacity $\mathrm{NiMH}$ and $\mathrm{NiCd}$ (both more prevalent in the previous period) but are less subject to losses and to the "memory effect", i.e. when the battery does not reach its full capacity anymore after a series of uncompleted charging processes (Schaefer, Weber, \& Voss, 2003). Also the voltage of the batteries stabilized around 3.6-3.7 V for the handsets released after 2000 , while it varied between $2.4,3.6,4.8,6,7.2,7.5 \mathrm{~V}$ for those from the previous period. These modifications enabled maintaining the electrical energy stored in the batteries practically the same, despite the miniaturization of the devices and without compromising functionality. ${ }^{13}$

\footnotetext{
${ }^{12}$ www.mobiForge.com . A good list of best-selling devices is available in Anonymous (2015). The Center for Future and Emerging Technologies at University of Salford provides useful information on analogue mobile phones (http://www.cntr.salford.ac.uk/comms/etacs_mobiles.php, last access 3/3/2015). Data on the full specifications of new handsets can also be accessed in specialized websites (e.g. www.gsmarena.com).

${ }^{13}$ Electrical energy $[\mathrm{Wh}]=$ Voltage $[\mathrm{V}] \times$ Capacity $[\mathrm{Ah}]$
} 


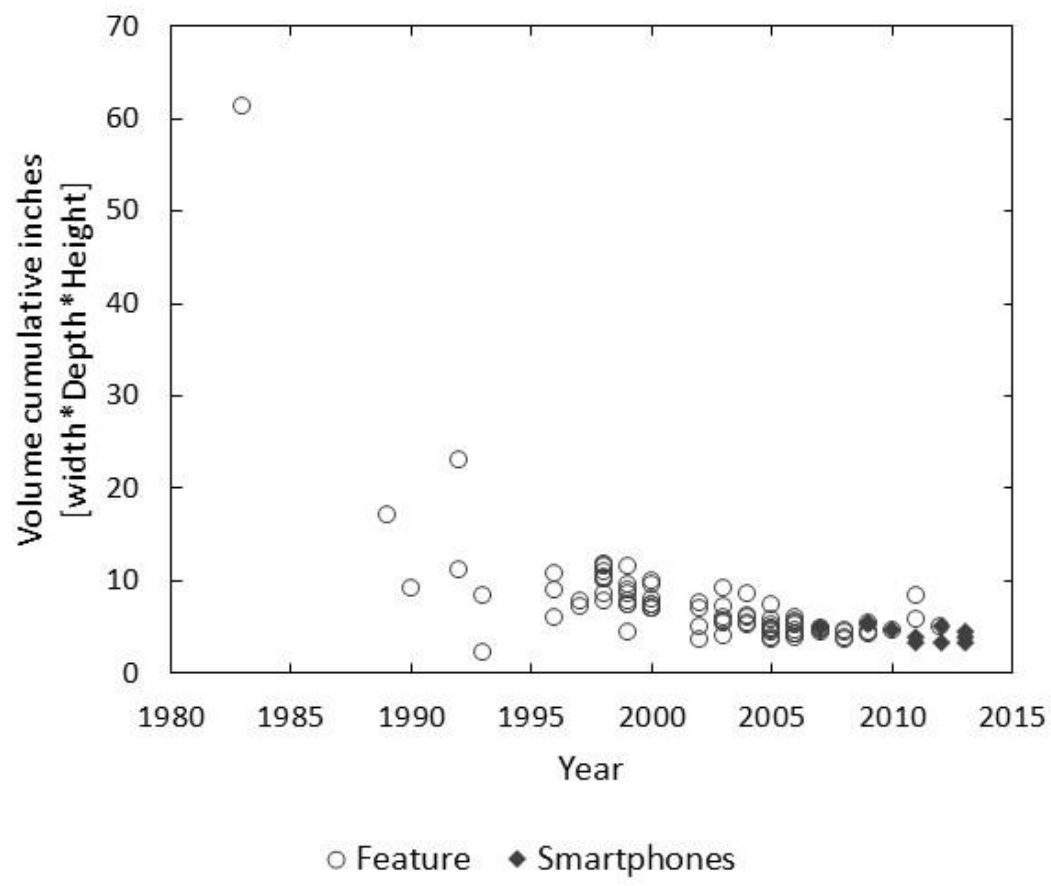

Fig. 8. The size of mobile phones over time ( $\mathrm{N}=101$ phones, among feature and smartphones). Data set collected by the author, see explanation on the sources in the text.

The autonomy of handsets has actually improved over time. Figure 9 shows the evolution of talk-time and the stand-by-time for the surveyed 90 feature phones, according to different battery capacities. ${ }^{14}$ The functionality of the mobile phone still depends on the capacity of its battery, as handsets equipped with higher storage capacity batteries have an increased talk-time and stand-by-time (see darker diamonds and squares in the top-right part of the graph). But the data also suggests that more recent devices (darker symbols) enjoy an improved autonomy when compared to the older ones (lighter symbols). This was only possible thanks to the reduction in power consumption obtained through the more efficient use of the energy stored in the battery. ${ }^{15}$

Cellphone energy efficiency has increased over time, as illustrated in Fig.10. The successive generations of phones have enabled longer talk-time and stand-by-time (not shown) per stored Watt-hour (Wh). In

\footnotetext{
${ }^{14}$ Other functionalities include internet connection (especially with smartphones) and text messages (see, e.g. Paiano, Lagioia, \& Cataldo, 2013). In this analysis we only cover talk-time and stand-by time, as well as computation performance for recent smartphones.

${ }^{15}$ Energy consumption $_{i}[\mathrm{~W}]=$ Energy $[\mathrm{Wh}] /$ Time $_{i}$ [minutes],$i=$ call; stand-by .
} 
effect, the evolution of the most efficient models at each time can be approached by a logistic growth curve. This hypothetical curve has a diffusion rate $(\Delta t)$ of 10 years and an inflection point $\left(\mathrm{t}_{0}\right)$ in 1997prior to the moment when the diffusion of cellphones reaches the inflection point in the Core in 1999 (see Section 5.1.) - when a larger number of the handsets sold in the market was already digital. Its takeoff coincides with the introduction of the first digital phones (e.g. Nokia 1011), suggesting that this was decisive to boost the efficiency of the phones from 100 to 180 minutes per Wh.

More recently, smartphones have further diversified the range of services provided by mobile phones, namely by dramatically extending the capacity to transfer and treat data. The dynamics of computation performances of the top-selling smartphones, here represented by the successful generations of Apple iPhone and Samsung Galaxy, are surveyed by comparing DMIPS (Dhrystone Million Instructions Per Second), which measures the number of program iterations completed per second. Data is directly available from independent tests and technical descriptions of the products provided by manufacturers. In its absence, it can be indirectly estimated by using average converting factors that approach DMIPS from the frequency $(\mathrm{MHz})$ of different generations of processors. ${ }^{16}$ The results show that the processing capacity of smartphones has evolved exponentially between 2007 and 2013 (Fig.11, left).

To analyze the evolution of energy consumption for computation by smartphones, the number of computations per milliwatt-hour ( $\mathrm{mWh}$ ) was estimated. Fig.11 (right) clearly shows a quick increase of processors performances per unit of energy used in the surveyed period. The improvement in the computational energy efficiency of smartphones followed a pace comparable to that for computers, doubling every 1-2 years (cf. Koomey et al., 2011). This allowed overcoming the constraints imposed by battery storage and providing the handsets with more features, contributing to the more widespread use of smartphones.

Therefore, the technological improvements of mobile phones over time enabled them to provide more services (talk and stand-by time, computation) and improve their energy efficiency. The energy consumption of handsets (feature or smart) in practice is, however, influenced by usage patterns. The next section estimates the average energy consumption of mobile phones by the mean of a field experiment.

\footnotetext{
${ }^{16}$ The relative performances of different generations of processors are often announced by mobile phone component suppliers (e.g. www.arm.com).
} 


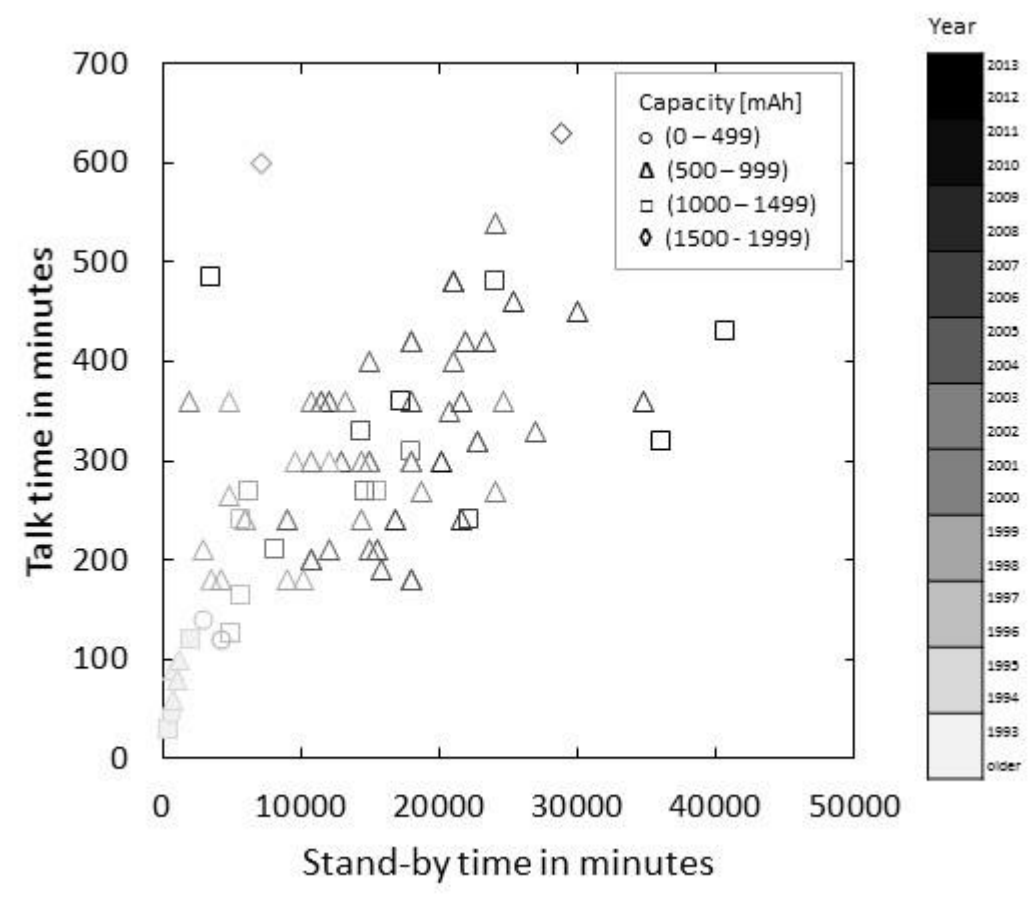

Fig. 9. The evolution of the autonomy of mobile phones in terms of talk time and stand-by time (in minutes). The gray color indicates the year and the shape of the marks corresponds to the energy storage capacity of the battery measured in milliampere-hour or mAh (see legend in the graph). Feature phones only $(\mathrm{N}=90)$.

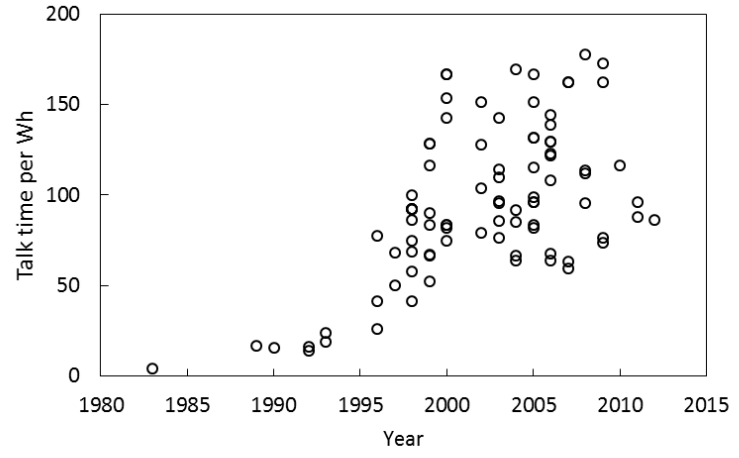

o Actual

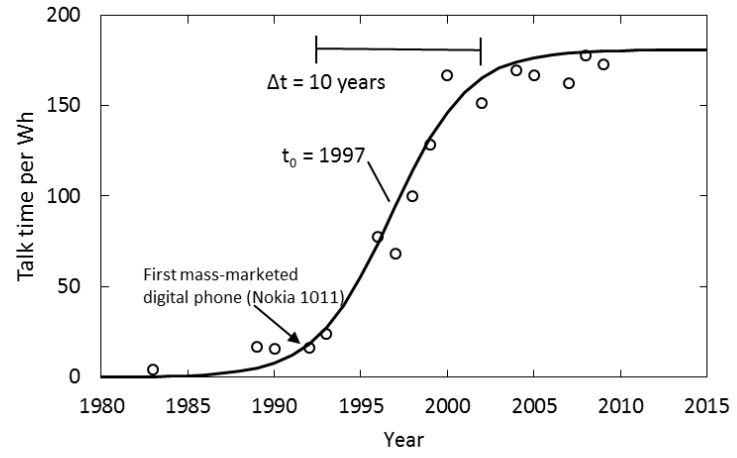

- Simple logistic function

- Efficiency frontier

Fig. 10. The evolution of talk time in minutes per Wh. Feature phones only $(N=90)$. In the right-hand, the logistic fit of the efficiency frontier - composed with the most efficient models-illustrates the evolution of the technology over time. 

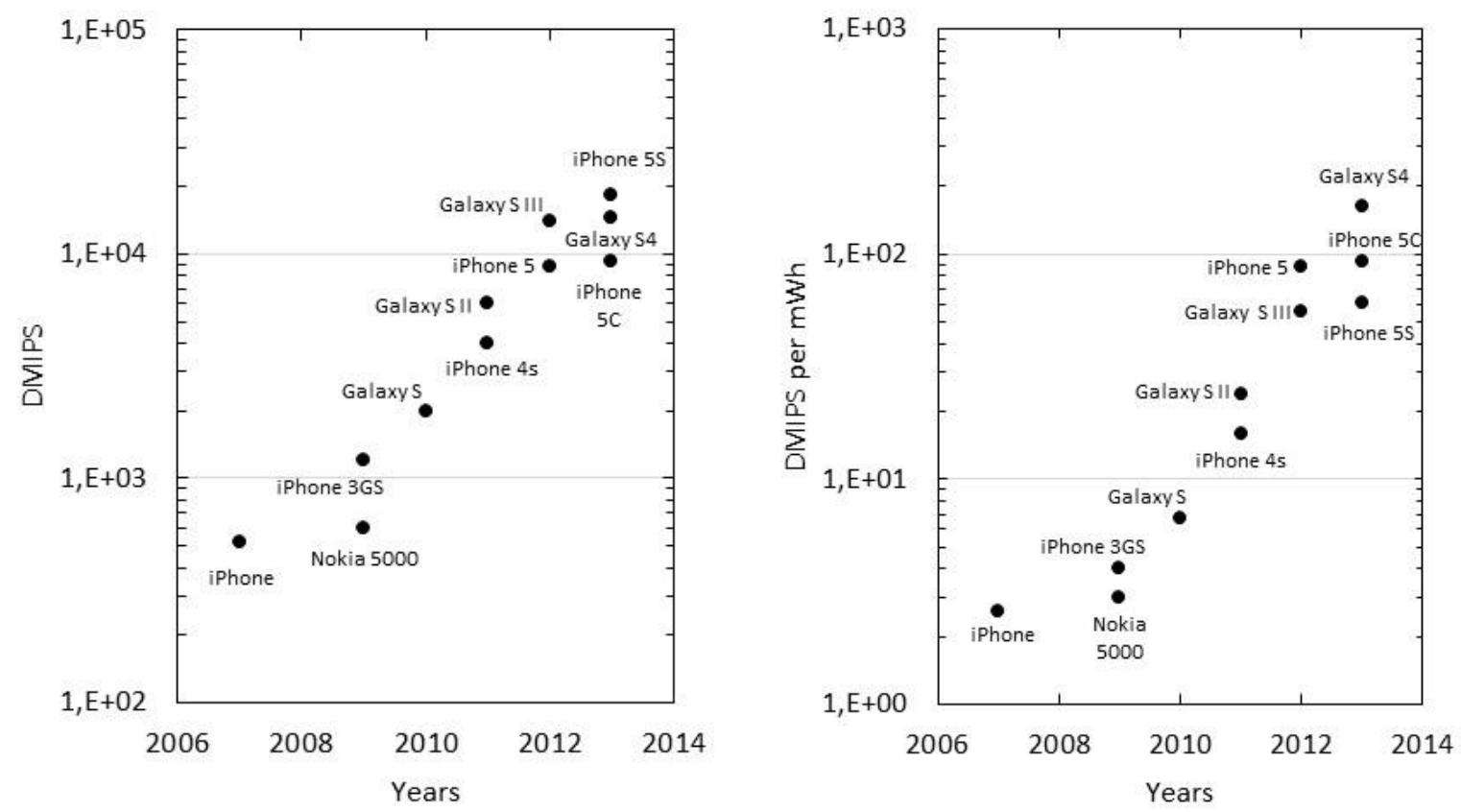

Fig. 11. Computational performances of smartphones in DMIPS (left) and DMIPS per mWh (right) between 2007 and 2013. Note: semi-logarithmic scales $(\mathrm{N}=11)$.

\subsubsection{Power capacity and energy consumption}

The aim of the experiment was to find the energy consumption of mobile phones. Another reason for conducting the experiment was the existing difference between the rated power and the real maximum power of the charging system.

The energy capacity and consumption of phones are estimated according to the results of a measurement conducted at the International Institute for Applied Systems Analysis (IIASA), an international research institute involving researchers from all over the world. The test focused on measuring the power and consumption of the battery charging system, which is the "common denominator" of every cellular phone, comparable across different types of phones irrespective of their energy efficiency, autonomy, functionality or any other feature (Horowitz et al., 2004). ${ }^{17}$ The protocol of

\footnotetext{
${ }^{17}$ The battery charging system converts AC electricity from the wall plug to extractable DC electricity that can be stored in the battery and used to power higher functions, such as transmitter circuits and user controls. The system has two main components: the power supply and the battery charger circuit. The power supply is external to the case of the phone and converts high-voltage AC electricity to low-voltage DC electricity. The battery charger circuit is
} 
the trial is further explained in Appendix 1. The sample consisted of 37 cellular phones with most of them released after 2004, the oldest being from 2002. The results are presented in Figures $12-13 .{ }^{18}$

Figure 12 (left-hand) shows the results for the rated and measured capacity of the mobile phones, given by the input power of the charger while recharging. The rated power is typically several times (around 310 times) the actual peak power. The maximum rated power averaged 34 Watts (12), whereas the maximum measured power $4.5 \mathrm{~W}$ (1.15)-standard deviation in brackets. In addition, the power used during the charging process varies according to the mix of modes of charge. ${ }^{19}$
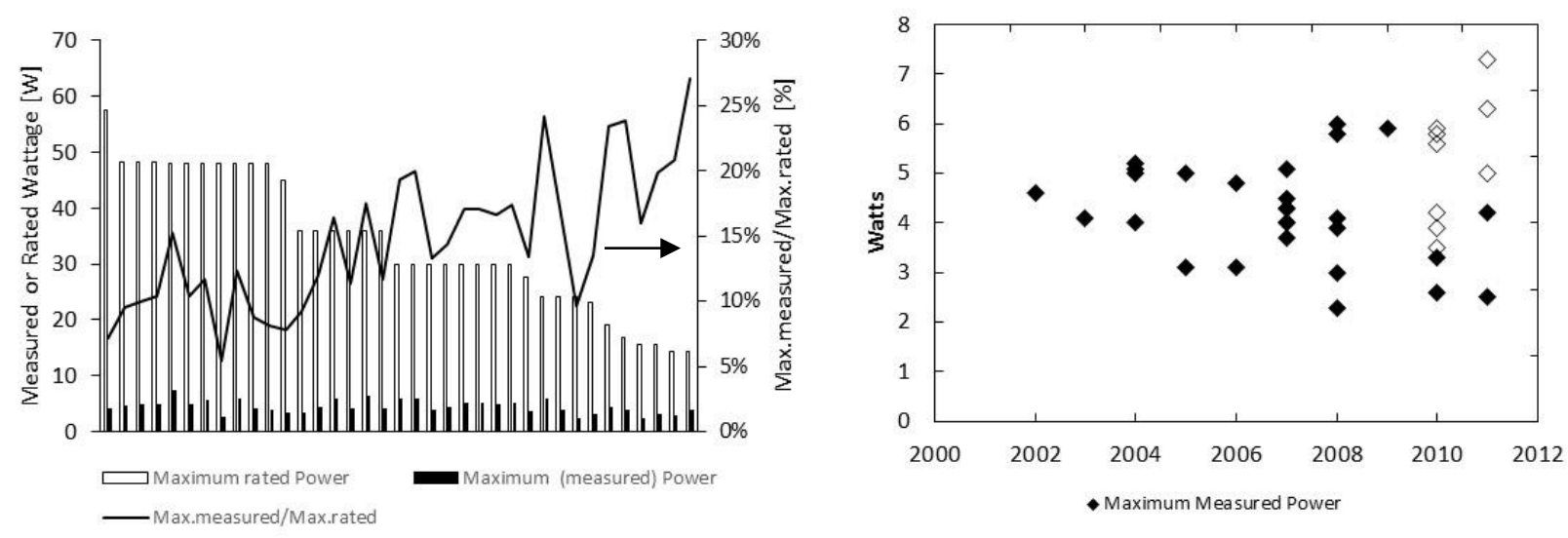

Fig. 12. On the left, rated versus measured maximum power of the mobile phones in Watts (every bar corresponds to one handset). On the right, maximum measured wattage by year of the device; smartphones on empty dots.

The evolution of the maximum capacity of the cellphones across time suggests a gradual increase since 2002 (Figure 12, right-hand). The trend found in the trials confirms the results of a previous study, the ECOS' 2004 (Horowitz et al., 2004) for the years between 2002 and 2003. More recently smartphones contributed significantly to the upward tendency in the measured power capacity. The ever-increasing speed of connections afforded by the new generation of phones allows fast data transfers, enlarging the

generally located inside the cell phone. Comprising safety and power management features to prevent accidents, it monitors and controls the electricity flow that goes into the battery. See: Horowitz et al., 2004.

${ }^{18}$ The Excel spreadsheet containing all the information concerning the tests is available for research purposes upon request from the author.

${ }^{19}$ When plugged in with no phone connected there is one power level, when plugged in and charging there is another power level, and when plugged in and connected to a cellphone but not charging (i.e., the battery is full) there is usually another power level. 
variety of services that can be supplied by a mobile phone, e.g. videoconferences, file downloads, email service, streaming video. Not surprisingly, this requires a larger capacity of the battery.

To calculate the annual electricity consumption of mobile phones, detailed data is normally needed on usage patterns of the handsets, as well as on the power consumption by modes (e.g. call, stand-by, text messaging, internet connection, off). If the latter is relatively easy to estimate from the product specifications provided by the manufacturers (see section 5.2.1), the data on the time of the calls and other modes is hardly ever available from operators since even aggregated numbers could reveal information regarding customer profiles (Schaefer et al, 2003). This problem has been circumvented in previous studies at the country level (Schaefer, Weber, \& Voss, 2003; Paiano, Lagioia, \& Cataldo, 2013) by creating different user profiles and assuming (with more or less statistical support) a distribution of subscribers by profile. In addition, it is necessary to estimate the losses of the charging process, which the same studies extrapolate from the results of experimental tests with real models. However, the use of this method to estimate the energy consumption of mobile phones worldwide has currently a series of hurdles: different countries are likely to show different usage patterns; market shares of the customer profiles can change from country to country; and there is a problem of aggregation of the information concerning modes and market shares of the profiles from countries into regions and into the world, which would probably require strong assumptions with weak (if any) statistical basis.

Alternatively, the present study measures the electricity consumption of mobile phones per charge and estimates the average annual consumption by taking into account the stated users (charging) habitudes. It is important to note that this analysis simplifies the patterns of usage of different categories of users and assumes that the average recharging behavior of the participants in the sample is representative of the situation worldwide. Low energy consumption per handset (limiting the range of plausible values), confrontation of the results with the values from the extant literature, and sensitivity analysis help to validate and improve confidence in the estimates found in this experiment.

Figure 13 shows the energy consumption per charge (left) and the estimated average annual consumption (right) for the 37 handsets, by year of acquisition. The measurements show that the consumption per charge decreased between 2000 and 2008. However, it has rebounded in the past 2 to 3 years, passing from 2-6 to 6-18 Wh, averaging 10 Wh during that period. This number compares with the $7 \mathrm{Wh}$ of average energy consumption per charge found in a different experimental test reported in Paiano, Lagioia, \& Cataldo (2013). The annual consumption was then calculated by asking users about their habits of charging the phone, especially the number of times they recharged their devices and if 
they waited until the battery is empty to recharge the handset (see Appendix 1 . for more details). ${ }^{20}$ The average annual consumption of the 37 phones was found to be $1.2 \mathrm{kWh}(0.72)$, though with high variations between observations as demonstrated by the standard deviation in brackets. The results show that smartphones are clearly reversing the consumption trend by pushing it towards $2.5-3 \mathrm{kWh}$, which is higher than the consumption of old mobile phones using low quality chargers. ${ }^{21}$

These values are well in the range of the numbers found in the literature. Malmodin et al. (2010) reported $3 \mathrm{kWh} /$ year of direct energy use citing a review of life-cycle analysis (LCA) of mobile phones (not differentiating between feature- and smart-phone) carried out by Ericsson/Sony Ericsson using both available and internal data from 1995 to 2009. Paiano, Lagioia, \& Cataldo (2013) estimate energy consumption per subscriber as varying between 0.42 and $3.95 \mathrm{kWh} /$ year, from low to high usage patterns, respectively. Older studies present more disparate estimates. For example, Horowitz et al. (2004) found an average power use of $6 \mathrm{kWh} /$ year by phones sold between 2002 and 2004 - though using very pessimistic assumptions concerning usage and charging of the phones, for instance assuming 12 hours per day of stand-by (charger left plugged in without being connected to the cellphone). Schaefer, Weber, \& Voss (2003), in turn, estimate energy consumption at $1.06 \mathrm{kWh} /$ year per subscriber (not including the stand-by consumption of chargers, as well), but this result depends to a large extent on the assumptions related to customer profiles and market shares.
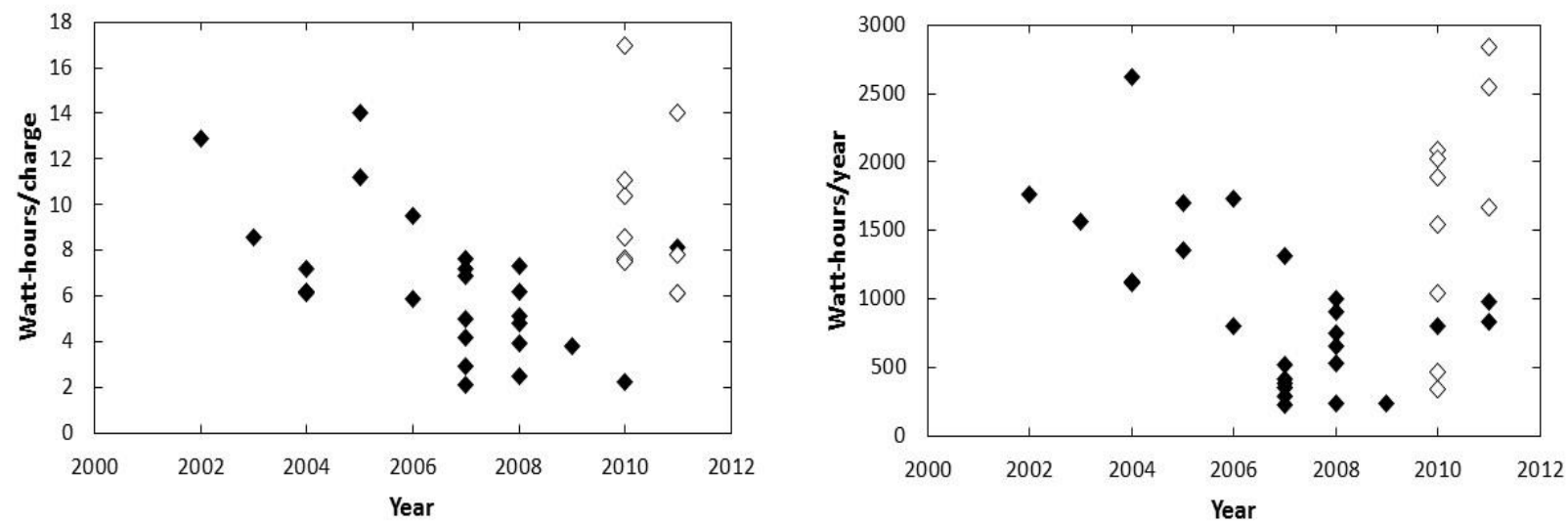

Fig. 13. Measured unit energy consumption per charge (left) and estimated annual consumption of cellular phones (right) by year of the device. Smartphones on empty dots.

\footnotetext{
${ }^{20}$ Energy consumption per year $=$ Average number of charges per week [\#] $\mathrm{x}$ Power consumption per charge $[\mathrm{Wh}] \mathrm{x}$ $i \mathrm{x} 52$ [weeks per year], $i=1$ (if user waits until the battery is empty to recharge the handset), 0.75 (otherwise).

${ }^{21}$ Actually, the energy consumed by letting the charger plugged into the grid even if the phone is unplugged (the socalled no-load) (Horowitz et al., 2004) was found to be near-zero for all the phones surveyed from 2002 to 2011. This is a progress compared to the older chargers tested in Schaefer, Weber, \& Voss (2003), which presented a stand-by power (of chargers) of $1.5 \mathrm{~W}$.
} 
Finally, the efficiency of the battery charger system was calculated by dividing the battery storage capacity (Wh) by the measured total consumption of the phone per charge (Wh). The total energy extractable from a fully charged battery was estimated from the information concerning the voltage and the wattage written on the battery and reported in an Excel spreadsheet. Figure 14 shows the observed efficiencies, covering a broad range from more than $90 \%$ to less than $30 \%$. The average efficiency of the charging process is around $49.85 \%$, though higher than the $27 \%$ found in the experiments with older models reported in Schaefer, Weber, \& Voss (2003). Results show that half of the energy power absorbed from the grid is in average lost in the charging process and only the other half is converted into service (call, stand-by, text message or internet connection).

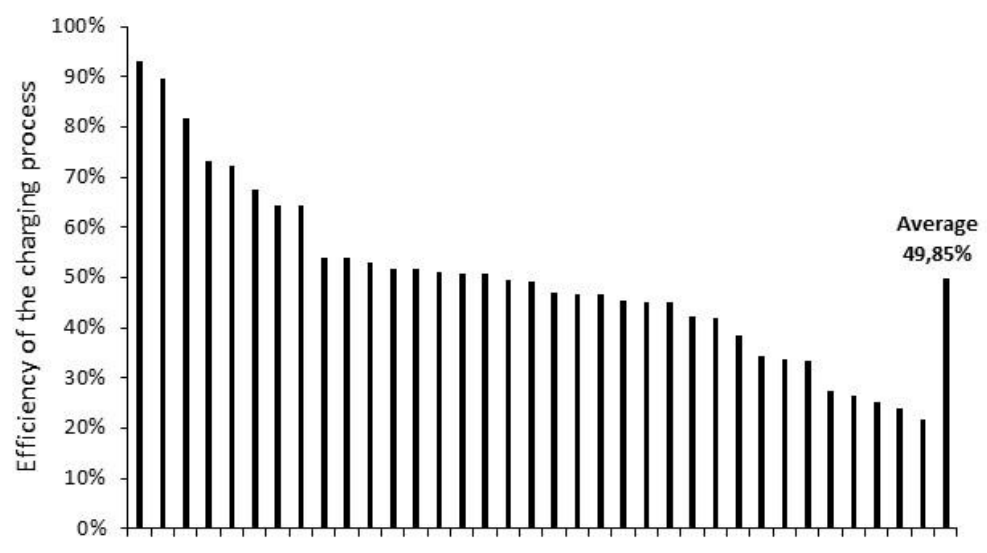

Fig. 14. Efficiencies of mobile phone charging processes

Therefore, the total installed capacity as well as the energy needs of mobile phones worldwide can be estimated with the information on the number of phones (using subscriptions as a proxy), unit capacity and average consumption - as discussed in the next points.

\subsection{Energy-related impacts of diffusion}

This section investigates the effect of the growth of mobile phones in energy demand. The measured power capacity of the phones was estimated in the previous sections at 4.5-6 W, which multiplied by 5.34 billion phones in operation in 2010 translates into $24-32 \mathrm{GW}$ of installed capacity worldwide. Likewise, the average consumption per phone of 1.2-1.5 kWh multiplied by all the phones in use gives a global consumption of 6-8 TWh. This is roughly equivalent to the production of a $1 \mathrm{GW}$ mid-size coal 
power plant, $1 \mathrm{GW}$ nuclear reactor, or even $3.15 \mathrm{GW}$ wind power capacity, running a year-round (GWEC, 2016).

Figure 15 presents the evolution of the direct cell phone energy use over the last decades, which is already measured in billion kilowatthours, showing a rapidly rising trend. However, the energy required by the infrastructure is also indispensable for mobile communication and must be added to the estimates of energy demand from phone charging.

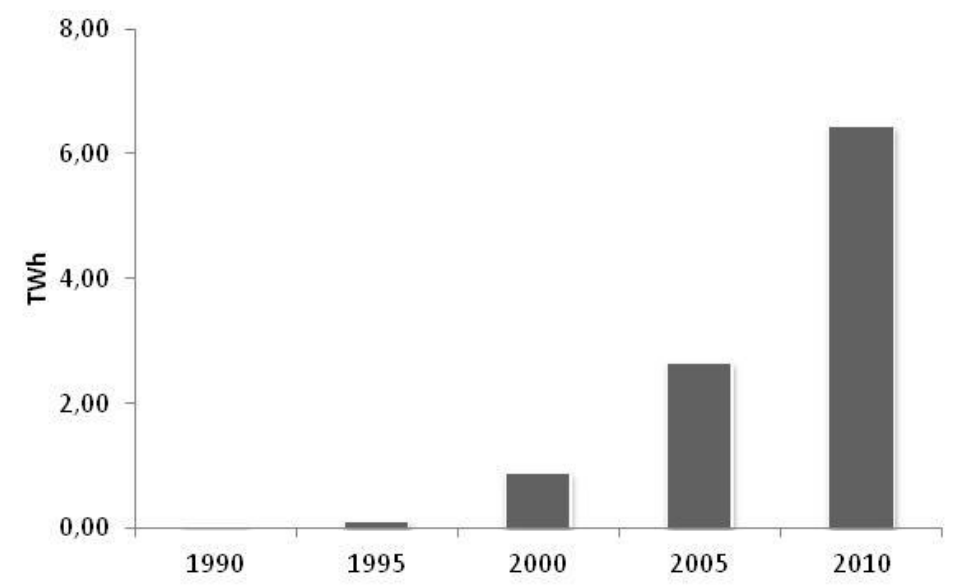

Fig. 15. Global energy consumption of handsets, in TWh (or billion kilowatthours).

To calculate the total amount of energy consumed for the entire network, it is necessary to have data on at least two major components (Scharnhorst, Hilty, \& Jolliet, 2006): the antenna controllers (e.g. base station controllers - BSC) and the antenna stations (e.g. base transceiver stations - BTS), which are more powerful and greater in number than the previous ones. The general procedure followed in previous studies consists of multiplying the average power consumption per component (especially BTSs) by the number of installations (Schaefer, Weber, \& Voss, 2003). ${ }^{22}$ However, the number of BTS can be more easily found for a specific country than for the entire world. What is more, their average consumption changes between different network standards. In fact, the world's infrastructure is far from being homogeneous and is rapidly evolving with the changes in mobile telecommunication technologies (e.g. $2 G, 3 G, 4 G)$, which are likely to alter the energy required to power the entire network. Alternatively, this

\footnotetext{
${ }^{22}$ Annual electrical power consumption of the network = Average power consumption [W] x 8,760 [h per year] $\mathrm{x}$ stock [number of installations].
} 
study uses the average annual consumption of a representative mobile phone network found in the literature.

The annual energy usage of mobile phone networks was calculated at $16 \mathrm{kWh}$ per subscriber (Malmodin et al., 2010). ${ }^{23}$ This value is an estimate of the energy needed for the Swedish network, which is dominated by $3 \mathrm{G}$ and $4 \mathrm{G}$ phones, whereas the global network is still mainly characterized by $2 \mathrm{G}$ technologies. However, Scharnhorst, Hilty, \& Jolliet (2006) shows that more recent network standards (e.g. $3 G$ UMTS R'99) can have similar energy requirements to the precedent 2G. Schaefer, Weber, \& Voss (2003) estimate the annual energy consumption of the $2 \mathrm{G}$ network in Germany at $15 \mathrm{kWh}$ per subscriber, in line with the reference value used in our study. Moreover, the authors show that the network's energy needs do not progress linearly with the number of subscriptions. In another study, Yu, Williams, \& Ju (2010) estimate the average power consumption of the mobile phone network in China by taking into account the same assumptions (1.1 kW per BTS plant), concluding that it is approximately 9.16 kWh per subscriber. Paiano, Lagioia, \& Cataldo (2013) finds that the annual energy requirements of the Italian network (a mix of $2 \mathrm{G}$ and $3 \mathrm{G}$ ) is $23.87 \mathrm{kWh}$ per subscriber, although with clearly higher assumptions on power consumption of BTS than those presented in the two previous studies (4 kW).

Considering an average annual energy consumption of $16 \mathrm{kWh}$ per subscriber and the number of subscriptions in 2010 of 5.34 billions, approximately 85.44 TWh was consumed by the mobile phone networks worldwide. If all networks had the same average energy requirements as in Italy, this result would be, instead, 127.47 TWh per year. Alternatively, it would be 48.9 TWh if the energy needs per subscriber were similar than those in China.

Therefore, in 2010, the total amount of energy consumed by the entire mobile phone sector (users and infrastructure) was approximately 93 TWh. ${ }^{24}$ Hence, the energy ascribed to end-user devices (6-8 TWh) represents only around $10 \%$ of total energy needs of the mobile phone system.

\footnotetext{
${ }^{23}$ The authors used data from previous life-cycle analyses (LCA) performed for the ICT sector, telecom operators' environmental reports, and internal data from an equipment manufacturer (Ericsson). This value includes electricity used by the networks and buildings and does not include energy consumption in operator activities, such as fuel for vehicles or diesel consumption by base stations at off-grid sites.

${ }^{24}$ The product of the number of phones in use (assumed equal to the number of subscriptions) multiplied by the sum of the average consumption per phone found in the field trials and the energy requirements of the network per subscriber: $5.34 \mathrm{bn} *(1.2$ to $1.5+16)=91.85$ to $93.45 \mathrm{TWh}$.
} 
If the current trends of mobile phone growth continue in the coming years, by 2020 , all other things being equal, the energy consumed by cellular phones and their infrastructure will reach an impressive 166 TWh. ${ }^{25,26}$ This is already similar to the final electricity consumption of Indonesia (167 TWh) in 2012, or about $1 \%$ of the total electricity consumption for the world (EIA, 2014). It is worth noting that this value only accounts for the average energy consumption of the handsets found in the experimental tests and the average energy consumption of a representative mobile phone network. Efficiency improvements may contribute to slow down the average consumption of the handsets and the infrastructure. However, the total energy consumption of the mobile phone sector can be higher in the future for two main reasons: the switch to new network standards (e.g. 3G, 4G) may increase the power consumption, and the growth of smartphones is likely to raise the average energy consumption of the handsets.

Figure 16 shows that smartphones are clearly substituting feature phones in annual sales. If the current trends are followed, they will dominate the market entirely by the year 2025 . This is already having a significant repercussion in their estimated share in total number of phones in use, passing from $3.6 \%$ to 29\% between 2007 and 2013 (Fig. 17).

Since the technology is changing fast, it is impossible to rigorously forecast what the impact of mobile phones will be in the next decade. Yet, if the current trends are followed, the penetration of mobile phones can have a non-negligible effect in the final energy demand.

\footnotetext{
${ }^{25}$ The product of the number of subscribers in 2020 multiplied by the energy requirements of the network per subscriber $(9.4 \mathrm{bn}$ phones $\times 16 \mathrm{kWh} /$ phone $=150 \mathrm{TWh})$ added to the electricity needed on charging $(16 \mathrm{TWh})$ makes up $166 \mathrm{TWh}$. But this value is subject to many uncertainties like the annual energy usage of the networks which is assumed to remain unchanged at $16 \mathrm{kWh}$ per phone (cf. Malmodin et al., 2010).

${ }^{26}$ A more complete perspective of the energy needs of mobile phones would have also included the energy used during the manufacturing stage of the phone, though the calculation is subject to even more uncertainty. An entire life-cycle analysis of cellular phones is out of the scope of this study. There are some estimates in the literature (see Malmodin et al., 2010; Yu, Williams, \& Ju, 2010; Scharnhorst, Hilty, \& Jolliet, 2006), though more analyses that take into account the growth of smartphones are needed in the future.
} 


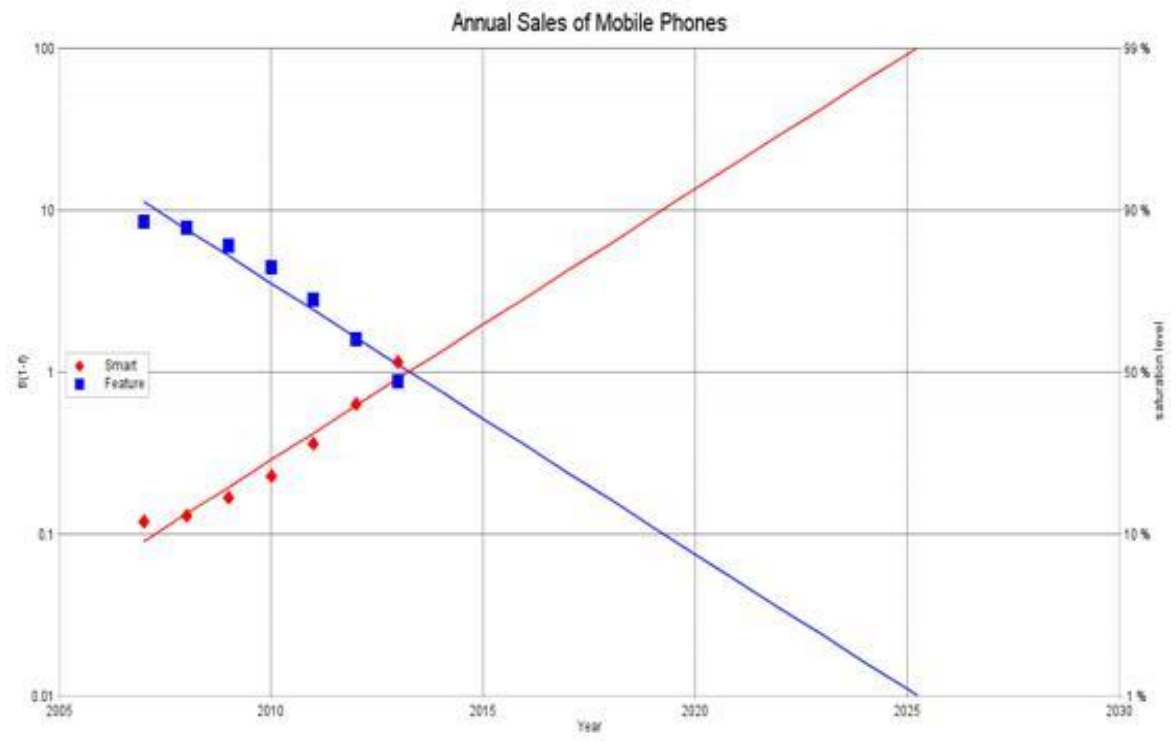

Fig.16. The substitution of feature phones by smartphones in the market (annual sales). Actual data (dots) and logistic curves (lines) plotted accordingly to the Fisher-Pry transformation. Data source: Gartner - Press releases (various years).

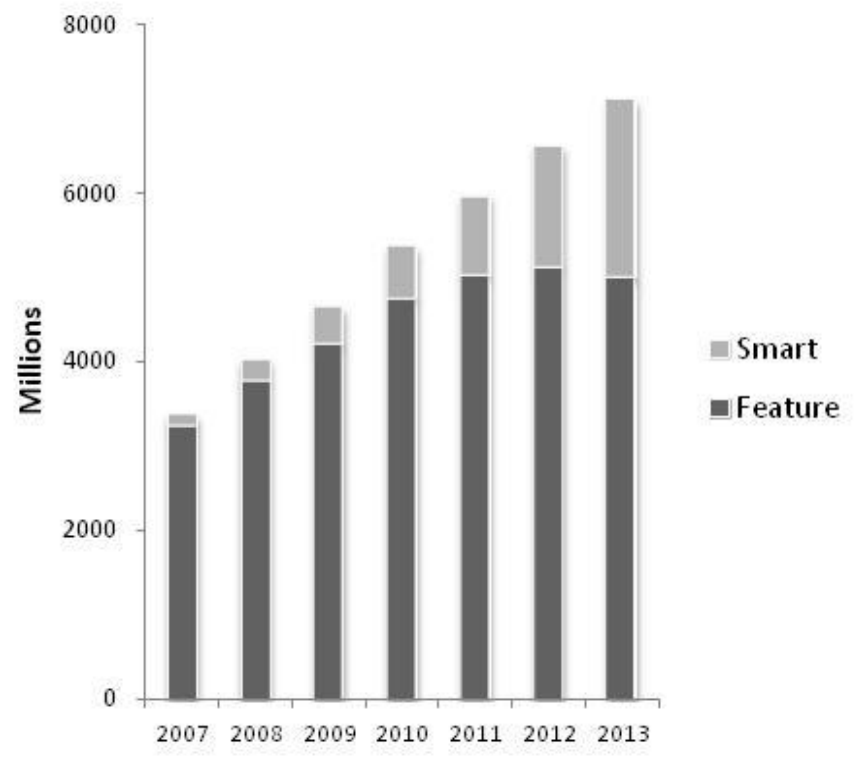

Fig.17. Number of mobile phones in use globally between 2007 and 2013, by type of phone. The number of phones in use is assumed equal to the number of subscriptions, and the lifetime of phones (smart or feature) is considered to be 3 years. Data source: Gartner - Press releases (various years). 


\subsection{Comparison of industry scaling with other technologies}

In this final section, the diffusion of mobile phones is compared with other technologies by looking at dynamics of industry scaling. The term 'scaling' refers to the technological growth that is both rapid and extensive, and can occur at multiple layers - technology unit and the industry as a whole (Wilson, 2012, 2009; Wilson \& Grubler, 2011). This is done by comparing the parameters $\mathrm{K}$ and $\Delta \mathrm{t}$ (extent-diffusion duration relationship) among different technologies. Previous studies found a strong relationship between the duration and the extent of diffusion of several supply and end-use energy technologies (Wilson, 2009; Wilson \& Grubler, 2011).

Figures 18 compare the parameters of growth of mobile phones with those of other technologies. Parameters come from the logistic fits to cumulative installed capacity of technologies. In the case of cellphones, annual production has been estimated globally and by region of origin from the evolution of the share of manufacturers. Normalizing raw data for the extent of the energy system (right-hand graph) allows comparing scaling dynamics between technologies that diffuses at different moments in time. ${ }^{27}$
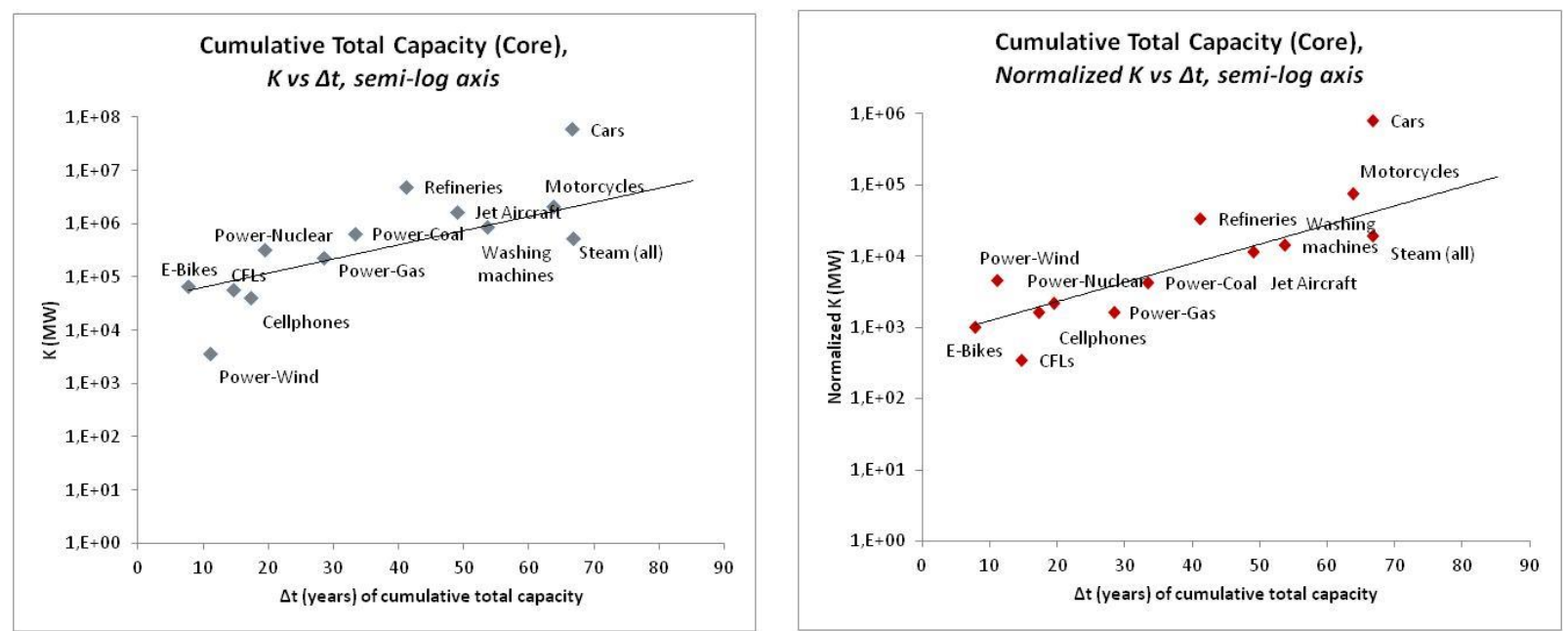

Fig. 18. Duration and scale of diffusion relationship for different technologies in the Core region. Data source: [mobile phones] Gartner - Press releases (2006-2011); In-Stat/MDR (2004); [other technologies] Bento, 2013; Wilson \& Grubler, 2011; Wilson, 2009, 2012.

The growth of mobile phones in terms of energy equivalent capacity was so intense that it is comparable to the industry scaling of other supply and end-use energy technologies. In fact cellphones follow the same extent-duration of diffusion relationship as other energy technologies. In spite of the very small

\footnotetext{
${ }^{27}$ The procedure consists to divide the saturation ( $\mathrm{K}$ in $\mathrm{MW}$ ) by the primary energy (in EJ) consumption of the energy system at the year $t_{0}$. The final result is an index number which makes possible to order technologies according to their impact on the energy system. See Wilson (2009) for more details.
} 
unit size, the diffusion of cellphones also reaches very high installed capacities because of the high number of units that have been deployed. This is a significant finding as it shows that it is possible to attain capacity levels similar to technologies like nuclear power plants or coal power plants within a relatively shorter period of time (left-end side of the trend in the graphs). This result suggests that the size of the incremental unit of capacity is unlikely to limit the potential impact of the innovation.

It can be argued that phone's small size, short lifetime and relatively low cost were important to enable such a fast and pervasive growth (Grubler, 2012). On the one hand, the challenges to starting the production of a small ("granular") innovation are normally less costly and complex than for a larger technology, as are the losses incurred in case of an unsuccessful entry in the market. On the other hand, the short lifetime of the equipment reduces the problem of lock-in to first models, which facilitates the incorporation of incremental improvements to the technology, thereby stimulating demand for replacing production. This is an important issue that is relevant for the deployment of technologies such as new low-carbon innovations and, thus, more studies are needed in the future about the influence that the size of the innovation has in the rate and extent of diffusion.

\section{Discussion and conclusions}

In spite of the broad recognition of the success of mobile phones' diffusion, the real extent of the growth and its impact on the energy system remained somewhat unknown. The purpose of this research was to bring some light to this, and ultimately to understand the likely influence of mobile communications on energy demand. Logistic models were used to examine the growth of production and demand of cellphones in order to give substance to the response to these questions.

It was demonstrated that cellular phones were produced and sold so intensively that this became the most popular technology, reaching indifferently rich and developing countries, and surpassing radio sets as the most used technology within a decade and half. The number of subscribers is saturating in both the Core and the Rim areas, while it reaches only half of the population in the Periphery, though it is rapidly catching up with the world average. The fact that there are now more subscribers in China or India than in the United States, where the number of subscribers was for a long time the highest in the world, underlines the democratic nature of the technology.

The success of cellular phones was only possible thanks to decreasing prices that turned devices affordable to an increasing population, enabling the spectacular development of demand. Other factors, 
in addition, contributed for the fast and widespread diffusion such as fast standardization that allowed network externalities, as well as technological improvements that made the phone more attractive by broadening the range of functionalities. The analysis of diffusion with more complex logistic models revealed the importance of the recent introduction of new features, such as internet connection, in the handsets to create another wave ("pulse") of growth within the mobile phone market.

The impact of cellphone diffusion was also assessed in terms of its implications for the energy system. A large number of end-use devices that marked the history of mobile phones were analyzed, which enabled tracing their physical, functional and energy efficiency evolution. A field trial was conducted to improve our knowledge of the evolution of unit capacity and consumption per phone across time. The results were validated through comparison with the values found in previous studies. They showed a gradual reduction in energy consumption between 2005 and 2009, though the trend was recently reversed with the arrival of smartphones in the market - which brought many new functionalities and services to the phone. It was possible to calculate the global capacity of mobile phones in operation, estimated between 24 and $32 \mathrm{GW}$, and the energy needed for charging all those devices which was evaluated at 6-8 TWh per year. The projection for the future is still very speculative because of the rapid evolution of the phones. For instance, battery technology advances and software optimization has contributed to limit the increase in the energy consumption of smartphones. But the diffusion of smartphones and more importantly the inclusion of the networks' consumption can raise significantly the estimate of energy needs.

The net effect in energy demand created by mobile phones is still very complex to estimate. The energy required by the supporting infrastructure is ten times higher than the direct consumption of the handsets, showing that mobile communication can have a sizeable impact on energy demand. This increase in final energy consumption must however be counterbalanced by the energy saved in the substitution of fixed 'landline' telephony, other technologies like computers (e.g. for internet access) or travels. Therefore, more research is needed in the future to determine the net effect of mobile communication on final energy consumption. This issue is particularly important for emerging economies where electricity needs are rapidly increasing. Cellphone is only a single technology in the wider field of $\mathrm{ICT}$, and thus the energy used by these technologies should particularly be taken into account in projections of energy demand in emerging economies (Sadorsky, 2012).

The main potential for reducing the mobile phone sector's energy requirement - apart from the production phase and end-of-life management not covered in this study - is in the end-use device and 
the energy consumption of the network. The no-load losses of the chargers - for a long time blamed for wasting large amounts of energy - have been partly solved thanks to voluntary agreements that led to the adoption of switch mode technology which reduced losses to around $0.2 \mathrm{~W}$. Similar agreements enabled introducing the standardized charger that can be re-used across different brands with positive impacts for the environment. These two examples are often cited to show the merits of a policy approach based on promoting voluntary agreements as opposed to a change in regulation.

Mobile phone devices however have the potential for further energy savings. Results from the field trial show that half of the energy power absorbed from the grid is in average lost in the charging process. It was also shown that the increase in functionalities, especially with smartphones, was more important than the increase in energy consumption. If this trend in energy efficiency keeps growing in the coming years, it may limit further increases in energy consumption of the handsets. The mobile phone network, on the other hand, presents the major potential for energy savings. Policy makers should emphasize the need to minimize the energy requirements of the network, namely by assessing energy efficiency as a critical parameter for the implementation of the latest network communication standards (e.g. 4G). Another issue of concern relates to the transition from $2 \mathrm{G}$ to $3 \mathrm{G} / 4 \mathrm{G}$, which, arguably, should be kept as short as possible in order to minimize energy consumption (Scharnhorst, Hilty, \& Jolliet, 2006).

More research is necessary on the energy demand of both the direct energy use of handsets and the infrastructure in order to allow more accurate projections of the energy-related impacts of mobile communication. The pattern of use should vary over time, as well as by region and by device (i.e. featured or "smart"). More precise estimates will be possible in the future with the availability of data namely on the evolution of smartphones and the national networks. In addition, the growing use of mobile phones to access the Internet increases the need for energy intensive server farms. Thus more research is needed to understand the contribution of mobile communication to increase the energy consumption of data centers.

Finally, the analysis shows that the diffusion of mobile phones was rapid and so intense that it reached levels of cumulative equivalent capacity comparable to those of energy supply technologies, despite the incomparable smaller size of the handsets. Therefore, a hypothesis was raised from this spectacular performance in order to discuss technology policies seeking to accelerate the penetration of low-carbon energy technologies. Specifically, this case suggests that small and affordable - granular - innovations can grow quickly and reach a high share of the population in a relatively short period of time. More empirical and theoretical work is needed in the future to test the validity of this research hypothesis. 


\section{Acknowledgments}

Grateful acknowledgement is made to the International Institute for Applied Systems Analysis for a grant in support of the research on which this article is based, and to DINÂMIA'CET. The author would also like to thank Arnulf Grubler, Charlie Wilson, Jonathan Koomey, Peter May-Ostendorp, Niels Schulz, Narasimha Rao, Keywan Riahi, Stella Bavier, and Pat Wagner. The usual disclaimer applies.

\section{Supplementary material}

The spreadsheets containing the data series and all the analysis can be found at http://webarchive.iiasa.ac.at/ bento .

\section{References}

Annafari, M. T., \& Bohlin, E. (2014). Empirical exploration of factors that determine multiple mobile phone subscriptions. International Journal of Mobile Communications, 12(1), 12-28.

Anonymous (2015). List of Best-selling mobile phones. Retrieved from http://en.wikipedia.org/wiki/List_of_best-selling_mobile_phones

Arthur, W. B. (1989). Competing Technologies : Increasing Returns and Lock-in by Historical Events. The Economic Journal, 99(1), 116-131.

Bain, J. S. (1956). Barriers to New Competition: Their Character and Consequences in Manufacturing Industries. Cambridge, MA: Harvard University Press.

Bass, F. (1969). A New Product Growth Model for Consumer Durables. Management Science, 15, 215227.

Bento, N. (2013). New Evidence in Technology Scaling Dynamics and the Role of the Formative Phase. (IIASA Interim Report IR-13-004). Laxenburg: International Institute for Applied Systems Analysis.

Bento, N. (2012). Electrical transition in transport: Extent, causes and prospects for diffusion of electric bicycles in China. (IIASA Interim Report IR-12-006). Laxenburg: International Institute for Applied Systems Analysis.

Bicycle Retailer and Industry News. (1998). Statistics. Retrieved from http://www.docstoc.com/docs/78211696/STATISTICS 
Bijker, W. E., \& Law, J. (1992). Shaping technology/building society: Studies in sociotechnical change. Cambridge, MA: MIT press.

Bohlin, A., Gruber, H., \& Koutroumpis, P. (2010). Diffusion of new technology generations in mobile communications. Information Economics and Policy, 22(1), 51-60.

Botelho, A., \& Pinto, L. C. (2004). The diffusion of cellular phones in Portugal. Telecommunications Policy, $28(5), 427-437$.

BOVAG-RAI. (2008). Mobility in Figures - Two-wheelers 2008/2009 (p. 62). Amsterdam: BOVAG-RAI Mobility Foundation. Retrieved from http://www.bovagcijfers.nl/bovag_cijfers_auto_en_2008.html

Chang, B.-Y., Li, X., \& Kim, Y. B. (2014). Performance comparison of two diffusion models in a saturated mobile phone market. Technological Forecasting \& Social Change, 86, 41-48.

David, P. A. (1985). Clio and the economics of Qwerty. American Economic Review, 75(2), 332-337.

Debecker, A., \& Modis, T. (1994). Determination of the Uncertainties in S-Curve Logistic Fits. Technological Forecasting and Social Change, 46, 153-173.

Economides, N. (1996). The Economics of Networks. International Journal of Industrial Organization, 14, 673-699.

Ericsson (2014). Ericsson Mobility Report. Stockholm. Retrieved from http://www.ericsson.com/ericssonmobility-report

EIA (2014). International energy statistics - online database. U.S. Department of Energy, Available at < http://www.eia.gov>.

Farrell, J., \& Saloner, G. (1985). Standardization, compatibility, and innovation. Round Journal of Economics, 16(1), 70-83.

Financial Times (2016). Apple primed to launch cheaper iPhone. March 20th.

Fisher, J. C., \& Pry, R. H. (1971). A Simple Substitution Model of Technological Change. Technological Forecasting and Social Change, 3, 75-88.

Gartner. (2013). Gartner Says Worldwide Mobile Phone Sales Declined 1.7 Percent in 2012. Press room, February 13. Retrieved from http://www.gartner.com/newsroom/id/2335616

Gastwirth, J. L. (1972). The Estimation of the Lorenz Curve and Gini Index. The Review of Economics and Statistics, 54(3), 306-316.

Geroski, P. A. (2000). Models of technology diffusion. Research Policy, 29, 603-626. 
Grajek, M., \& Kretschmer, T. (2009). Usage and diffusion of cellular telephony, 1998-2004. International Journal of Industrial Organization, 27(2), 238-249.

Griliches, Z. (1957). Hybrid Corn : An Explanatory in the Economics of Technological Change. Econometrica, 48, 501-522.

Gruber, H., \& Verboren, F. (2001). The diffusion of mobile telecommunications services in the European Union. European Economic Review, 45(3), 577-588.

Grubler, A. (2012). Energy transitions research: Insights and cautionary tales. Energy Policy, 50, 8-16.

Grubler, A. (1998). Technology and Global Change. Cambridge: Cambridge University Press.

GWEC (2016). Global Wind Report: Annual Market Update 2015. Global Wind Energy Council, Brussels.

Hausman, J. (1997). Valuing the Effect of Regulation on New Services in Telecommunications. Brookings Papers: Microeconomics.

Hilbert, M., \& López, P. (2012). Info Capacity| How to Measure the World's Technological Capacity to Communicate, Store and Compute Information? Part II: Measurement Unit and Conclusions. International Journal of Communication, 6, 936-955.

Hilbert, M., \& López, P. (2011). The World's Technological Capacity to Store, Communicate, and Compute Information. Science. 332, 6025. April 1, 60-65.

Horowitz, N., Ostendorp, P., Foster, S., \& Calwell, C. (2004). Cellular Phones: Advancements in Energy Efficiency and Opportunities for Energy Savings. Natural Resources Defense Council. Retrieved from http://www.nrdc.org/air/energy/energyeff/cellphones.pdf

Horta, A., Fonseca, S., Truninger, M., Nobre, N., \& Correia, A. (2016). Mobile phones, batteries and power consumption: An analysis of social practices in Portugal. Energy Research \& Social Science, 13, 15-23.

In-Stat/MDR. (2004). Riding the Growth Curve: Annual Mobile Handset Forecast. Report details. Retrieved from www.instat.com/press.asp?Sku=IN0401700WH\&ID=1031

ITU. (2014). ITU World Telecommunication / ICT Indicators Database 2014. International Telecommunication Union, United Nations. Retrieved from http://www.itu.int/en/ITUD/Statistics/Documents/statistics/2014/ITU_Key_2005-2014_ICT_data.xls

ITU. (2013). ITU World Telecommunication / ICT Indicators Database 2013. International Telecommunication Union, United Nations. Retrieved from http://www.itu.int/en/ITUD/Statistics/Documents/statistics/2013/ITU_Key_2005-2013_ICT_data.xls

ITU. (2011). ITU World Telecommunication / ICT Indicators Database 2011. International Telecommunication Union, United Nations. Retrieved from http://www.itu.int/ITUD/ict/publications/world/world.html 
JAMA. (2011). Online database. Japan Automobiles Manufacturers Association. Retrieved from http://www.jama-english.jp/about/org.html

Jang, S.-L., Dai, S.-C., \& Sung, S. (2005). The pattern and externality effect of diffusion of mobile telecommunications: the case of the OECD and Taiwan. Information Economics and Policy, 17(2), 133-148.

Katz, M. L., \& Shapiro, C. (1985). Network externalities, competition and Compatibility. American Economic Review, 75(3), 424-440.

Kauffman, R. J., \& Techatassanasoontorn, A. A. (2009). Understanding early diffusion of digital wireless phones. Telecommunications Policy, 33(8), 432-450.

Kemeny, P., Munro, P.G., Schiavone, N., van der Horst, G., \& Willans, S. (2014). Community Charging Stations in rural sub-Saharan Africa: Commercial success, positive externalities, and growing supply chains. Energy for Sustainable Development, 23, 228-236.

Koomey, J. G., Berard, S., Sanchez, M., \& Wong, H. (2011). Implications of historical trends in the electrical efficiency of computing. Annals of the History of Computing, IEEE, 33(3), 46-54.

Liebowitz, S. J., \& Margolis, S. E. (2000). Path Dependence, Lock-In, and History. Retrieved from http://www.utdallas.edu/ liebowit/palgrave/palpd.html

Liikanen, J., Stoneman, P., \& Toivanen, O. (2004). Intergenerational effects in the diffusion of new technology: the case of mobile phones. International Journal of Industrial Organization, 22(8-9), 1137-1154.

Ling, R. (2004). The mobile connection: The cell phone's impact on society. San Francisco: Morgan Kaufmann.

Malmodin, J., Moberg, Å., Lundén, D., Finnveden, G., \& Lövehagen, N. (2010). Greenhouse Gas Emissions and Operational Electricity Use in the ICT and Entertainment \& Media Sectors. Journal of Industrial Ecology, 14(5), 770-790.

Marchetti, C., \& Nakicenovic, N. (1979). The dynamics of energy systems and the logistic substitution model. Laxenburg, Austria: IIASA.

Meade, N., \& Islam, T. (2015). Forecasting in telecommunications and ICT-A review. International Journal of Forecasting, 31, 1105-1126.

Meyer, P. (1994). Bi-logistic growth. Technological Forecasting and Social Change, 47(1), 89-102.

Meyer, P. S., \& Ausubel, J. H. (1999). Carrying capacity: a model with logistically varying limits. Technological Forecasting and Social Change, 61(3), 209-214.

Modis, T. (2002). Forecasting the growth of complexity and change. Technology Forecasting \& Social Change, 69(4), 377-404. 
Paiano, A., Lagioia, G., \& Cataldo, A. (2013). A critical analysis of the sustainability of mobile phone use. Resources, Conservation and Recycling, 73, 162-171.

Riikonen, A., Smura, T., Kivi, A., \& Töyli, J. (2013). Diffusion of mobile handset features: Analysis of turning points and stages. Telecommunications Policy, 37(6), 563-572.

Rouvinen, P. (2006). Diffusion of digital mobile telephony: Are developing countries different?. Telecommunications Policy, 30(1), 46-63.

Sadorsky, P. (2012). Information communication technology and electricity consumption in emerging economies. Energy Policy, 48, 130-136.

Schaefer, C., Weber, C., \& Voss, A. (2003). Energy usage of mobile telephone services in Germany. Energy, 28(5), 411-420.

Scharnhorst, W., Hilty, L. M., \& Jolliet, O. (2006). Life cycle assessment of second generation (2G) and third generation (3G) mobile phone networks. Environment International, 32(5), 656-675.

Shapiro, C., \& Varian, H. R. (1998). Information Rules: A Strategic Guide to the Network Economy. Boston: Harvard Business School Press.

Singh, S. K. (2008). The diffusion of mobile phones in India. Telecommunications Policy, 32(9), 642-651.

Sovacool, B. K. (2016). How long will it take? Conceptualizing the temporal dynamics of energy transitions. Energy Research \& Social Science, 13, 202-215.

Stoneman, P. (2002). The Economics of Technological Diffusion. Oxford: Blackwell Publishers Ltd.

The Economist (2015). Special Report: Energy and Technology. January 17th-23rd.

U.S. Census Bureau. (2010). Online database. Retrieved from www.census.gov/compendia/statab/2010/tables/10s1062.xls

UN Population Division. (2011). World Population Prospects, the 2010 Revision. United Nations. Retrieved from http://esa.un.org/unpd/wpp/Documentation/pdf/WPP2010_Highlights.pdf

Watanabe, C., Moriyama, K., \& Shin, J.-H. (2009). Functionality development dynamism in a diffusion trajectory: A case of Japan's mobile phones development. Technological Forecasting \& Social Change, 76(6), 737-753.

Watanabe, C., Kondo, R., Ouchi, N., Wei, H., \& Griffy-Brown, C. (2004). Institutional elasticity as a significant driver of IT functionality development. Technological Forecasting and Social Change, 71(7), 723-750.

Wilson, C. (2012). Up-scaling, formative phases, and learning in the historical diffusion of energy technologies. Energy Policy, 50, 81-94. 
Wilson, C. (2009). Meta-analysis of unit and industry level scaling dynamics in energy technologies and climate change mitigation scenarios. Laxenburg, Austria: International Institute for Applied Systems Analysis (IIASA).

Wilson, C., \& Grubler, A. (2011). Lessons from the history of technology and global change for the emerging clean technology cluster (Interim Report No. IR-11-001). Laxenburg, Austria: IIASA.

World Bank. (2011). Online database. World Bank.

Yoo, Y., Lyytinen, K., \& Yang, H. (2005). The role of standards in innovation and diffusion of broadband mobile services: The case of South Korea. The Journal of Strategic Information Systems, 14(3), 323-353.

Yu, J., Williams, E., \& Ju, M. (2010). Analysis of material and energy consumption of mobile phones in China. Energy Policy, 38(8), 4135-4141.

\section{Appendix 1. Field experiment - Test procedure summary}

The aim of the experiment test was to assess the real electrical power required in the charging process of the handsets in order to estimate their energy usage. For this purpose, 37 different devices were tested: 35 different models and three similar Nokia 1100s, the world's best-selling cellphone, used in different continents (Europe and South America). The sample is composed by 27 GSMs and 10 UMTSs. The tested models were not brand-new and have been used to some extent. The choice of the sample sought to reproduce the conditions that can be found in reality. The following electrical parameters were monitored with the help of an electricity usage monitor (of a "Kill A Watt" type) during an entire recharge of the mobile phones: the wattage absorbed from the power grid (after 1 minute, 10 minutes and 5 hours) and the total power consumed in the charging process.

The test procedure uses the same methodology as that of the 2004 ECOS study for the Natural Resources Defense Council (Horowitz et al., 2004), in order to allow the maximum comparison with this study. The main features of the test are explained below.

The measurements were taken with the cellphone turned off, starting with the battery fully discharged, so that only the battery charging system was enabled during the test. The instantaneous power use and total electricity consumption of the cellphone were measured over a 5-hour period, comprising the stage of active charging of the battery (charge mode) and low-power mode after the battery is fully charged (maintenance mode). The no-load (stand-by) mode was also measured corresponding to the average consumption of a charger with no cellphone attached (measured over a 5-minute period). 
In addition, the mobile phone users were asked about the number of times per week they charged their devices, and if they waited until the battery was empty to charge it again. When they did not wait until the battery was empty, an average charge of three-quarters of the battery was assumed. This information allowed the estimation of the weekly consumption of the phone and, consequently, the annual consumption, by multiplying that value by 52 weeks. Table A.1 shows a statistical summary of the main parameters surveyed in the field test.

\begin{tabular}{lccccc}
\hline Parameters & Obs. & Minimum & Mean & Maximum & St.Dev. \\
\hline Maximum nominal output power of chargers [W] & 37 & 14.4 & 34.0 & 57.5 & 12.06 \\
Total consumption per charge [Wh] & 37 & 2.1 & 7.3 & 17.0 & 3.41 \\
Average Watts [W] & 37 & 0.42 & 1.49 & 3.40 & 0.72 \\
Maximum Watts [W] & 37 & 2.30 & 4.46 & 7.30 & 1.15 \\
Smartphones - Total consumption per charge [Wh] & 10 & 6.1 & 9.8 & 17.0 & 3.43 \\
Smartphones - Maximum Watts [W] & 10 & 3.3 & 5.08 & 7.3 & 1.32 \\
Efficiency of batteries [\%] & 35 & 22 & 47 & 93 & 0.18 \\
Consumption per year [Wh] & 37 & 228 & 1129 & 2839 & 719.44 \\
\hline
\end{tabular}

Table A.1. Statistical summary of the main results obtained in the experiment test 